\title{
Analysis of respiratory and systemic immune responses in COVID-19 reveals mechanisms of disease pathogenesis
}

Peter A. Szabo ${ }^{1,2^{*}}$, Pranay Dogra ${ }^{1,2 *}$, Joshua I. Gray ${ }^{1,2^{*}}$, Steven B. Wells ${ }^{3 *}$, Thomas J. Connors $^{5}$, Stuart P. Weisberg ${ }^{7}$, Izabela Krupska ${ }^{3}$, Rei Matsumoto ${ }^{1,4}$, Maya M.L. Poon ${ }^{1,10}$, Emma Idzikowski ${ }^{5}$, Sinead E. Morris ${ }^{7}$, Chloé Pasin ${ }^{7}$, Andrew J. Yates ${ }^{7}$, Amy $\mathrm{Ku}^{7}$, Michael Chait $^{7}$, Julia Davis-Porada ${ }^{10}$, Jing Zhou ${ }^{9}$, Matthew Steinle ${ }^{9}$, Sean Mackay ${ }^{9}$, Anjali Saqi ${ }^{7}$, Matthew Baldwin ${ }^{6}$, Peter A. Sims ${ }^{3,8}$ and Donna L. Farber ${ }^{1,2,4}$

${ }^{1}$ Columbia Center for Translational Immunology, Columbia University Irving Medical Center, New York, NY 10032

${ }^{2}$ Department of Microbiology and Immunology, Columbia University Irving Medical Center, New York, NY 10032

${ }^{3}$ Department of Systems Biology, Columbia University Irving Medical Center, New York, NY 10032

${ }^{4}$ Department of Surgery, Columbia University Irving Medical Center, New York, NY 10032

${ }^{5}$ Department of Pediatrics, Columbia University Irving Medical Center, New York, NY 10032

${ }^{6}$ Department of Medicine, Columbia University Irving Medical Center, New York, NY 10032

${ }^{7}$ Department of Pathology and Cell Biology, Columbia University Irving Medical Center, New York, NY 10032

${ }^{8}$ Department of Biochemistry and Molecular Biophysics, Columbia University Irving Medical Center, New York, NY 10032

${ }^{9}$ IsoPlexis Corporation, Branford, CT 06405

${ }^{10}$ Medical Scientist Training Program, Columbia University

*Equal Contribution (Columbia- COVID-19 airway immunity team)

\section{SUMMARY}

Immune responses to respiratory viruses like SARS-CoV-2 originate and function in the lung, yet assessments of human immunity are often limited to blood. Here, we conducted longitudinal, high-dimensional profiling of paired airway and blood samples from patients with severe COVID-19, revealing immune processes in the respiratory tract linked to disease pathogenesis. Survival from severe disease was associated with increased $\mathrm{CD} 4^{+} \mathrm{T}$ cells and decreased monocyte/macrophage frequencies in the airway, but not in blood. Airway $\mathrm{T}$ cells and macrophages exhibited tissue-resident phenotypes and activation signatures, including high level expression and secretion of monocyte chemoattractants CCL2 and CCL3 by airway macrophages. By contrast, monocytes in blood expressed the CCL2-receptor CCR2 and aberrant $\mathrm{CD}_{163}{ }^{+}$and immature phenotypes. Extensive accumulation of $\mathrm{CD} 163^{+}$monocyte/macrophages within alveolar spaces in COVID-19 lung autopsies suggested recruitment from circulation. Our findings provide evidence that COVID-19 pathogenesis is driven by respiratory immunity, and rationale for site-specific treatment and prevention strategies. 
medRxiv preprint doi: https://doi.org/10.1101/2020.10.15.20208041; this version posted October 19, 2020. The copyright holder for this preprint (which was not certified by peer review) is the author/funder, who has granted medRxiv a license to display the preprint in perpetuity.

All rights reserved. No reuse allowed without permission.

\section{INTRODUCTION}

The novel respiratory virus SARS-CoV-2 has resulted in devastating impacts to the world's population, both as a result of morbidity and mortality caused by COVID-19, as well as the life-altering measures implemented to mitigate spread. While the majority of infected individuals (>90\%) develop a self-limiting disease and recover, approximately 5-10\% of individuals develop severe respiratory disease marked by lung infiltrates and reduced oxygen saturation, which can progress to acute respiratory distress syndrome (ARDS), multi-organ failure, and death (Wu and McGoogan, 2020). Risk factors for severe COVID-19 include older age and co-morbidities like obesity and diabetes, although younger and previously healthy individuals can also be susceptible (Cummings et al., 2020; Davies et al., 2020). For individuals who recover from self-limiting illness, the immune system acts in a coordinated fashion to clear the virus and establish virus-specific immunity (Moderbacher et al., 2020). However, the role of the immune response in the pathogenesis of severe COVID-19 remains unclear, and understanding this phenomenon is urgently required to develop new treatment and prevention strategies.

A key aspect of the immune response to respiratory virus infection is the activation and mobilization of immune cells to the lung for viral clearance. Innate immune responses are initiated within infected lung epithelial cells and local immune cells, including tissue resident alveolar macrophages and infiltrating monocytes and granulocytes (Yoo et al., 2013). The initial production of pro-inflammatory cytokines in the lung can precipitate cytokine storms in severe respiratory infections (Teijaro et al., 2011b). Adaptive immune responses are also mobilized in the lung; antigen-loaded dendritic cells migrate from the infected lung to the draining lymph node where they prime $\mathrm{CD} 4^{+}$and $\mathrm{CD}^{+} \mathrm{T}$ cells. The resultant effector $\mathrm{T}$ cells traffic to the lung to 
1 mediate clearance of infected cells in situ (Yoo et al., 2013). A proportion of these lung effector

2 T cells develop into tissue resident memory $\mathrm{T}$ cells (TRM), which are retained in the lung and

3 can mediate rapid protective responses upon viral challenge in mouse models (Teijaro et al.,

4 2011a; Turner et al., 2014; Turner and Farber, 2014; Wu et al., 2014). TRM in mice and humans

5 are phenotypically and transcriptionally distinct from circulating effector-memory (TEM) cells

6 (Kumar et al., 2017; Mackay et al., 2016; Masopust and Soerens, 2019). In adult lungs, TRM are

7 the predominant $\mathrm{T}$ cell subset and persist in stable frequencies throughout life (Kumar et al.,

8 2018), suggesting a crucial role in protection to respiratory pathogens. Moreover, CD4 ${ }^{+} \mathrm{TRM}-$

9 like cells in the airway are required for protection against SARS-CoV-1 in mice (Zhao et al., 2016). At present, we lack information on the role of resident immune cells, including alveolar macrophages and lung TRM in protection against SARS-CoV-2 infection, and their function in the pathogenesis of severe COVID-19.

Studies of the immune response to SARS-CoV-2 have examined innate and adaptive immune cells, as well as soluble mediators in blood and plasma of infected individuals, revealing elevated levels of pro-inflammatory cytokines (Hadjadj et al., 2020; Laing et al., 2020) and robust virus-specific adaptive immune responses. Virus-specific $\mathrm{CD}^{+}$and $\mathrm{CD}^{+} \mathrm{T}$ cells are found in most infected individuals with varying disease severities and persist following recovery

18 (Grifoni et al., 2020; Thieme et al., 2020; Weiskopf et al., 2020). Antibodies specific for different viral proteins, including anti-Spike $(\mathrm{S})$ protein-specific neutralizing antibodies (Long et al., 2020; Ni et al., 2020), also persist after resolution. How these systemic immune responses relate to innate and adaptive immunity in the respiratory tract is unclear and difficult to assess. 
1 from 15 patients with severe COVID-19, along with control airway and blood samples. We

2 identified robust innate and adaptive immune responses in the airway, which were distinct from

3 blood in cellular composition, function and transcriptional profile. Notably, increased

4 frequencies $\mathrm{CD} 4^{+} \mathrm{T}$ cells and decreased frequencies monocytes/macrophages in airways were

5 associated with survival and younger age, suggesting key roles for these cells at the infection

6 site. COVID-19 airways contained activated TRM, high frequencies of inflammatory tissue

7 monocytes/macrophages, and supranormal levels of the monocyte chemoattractant cytokines

8 CCL2, CCL3, and CCL4 - all lacking in blood, which contained predominant populations of

9 immature monocytes. Excessive macrophage/monocyte content in COVID-19 lung autopsies

10 compared to control lungs provide evidence for dynamic monocyte recruitment to the respiratory

11 tract. Our results reveal compartmentalization of innate and adaptive immune responses in the

12 respiratory tract of COVID-19, which drives peripheral immune cell infiltration and disease 13 pathogenesis. 


\section{RESULTS}

\section{Obtaining paired airway and blood samples from severe COVID-19 patients}

During the height of the pandemic in New York City, between April and June 2020, we enrolled patients from adult and pediatric intensive care units at New York Presbyterian hospital with severe COVID-19 (confirmed by positive SARS-CoV-2 PCR). Enrolled patients required mechanical ventilator support enabling us to obtain paired airway and blood samples longitudinally for up to 10 days during their hospitalization (average 6-7 sample days per patient). Sampling for each patient began within 24-36 hours of intubation. Patients represented a broad age range (14-84 yrs) and 8/15 (53\%) died during enrollment or soon after (Table S1). Enrolled COVID-19 patients exhibited similar clinical severity measures regardless of outcome; the extent of ARDS, inflammation, neutrophil levels and comorbidities were similar between deceased patients and those who survived, while median age differed significantly (72yrs, deceased; 39yrs, survived). All patients developed robust SARS-CoV-2-specific neutralizing antibodies as measured in plasma (Weisberg et al., 2020).

Airway samples were obtained using a saline wash of the endotracheal tube performed daily as part of clinical care, which we have previously shown contain respiratory immune cell populations (Connors et al., 2018; Connors et al., 2016). A total of 141 paired blood and airway cell preparations were analyzed by high-dimensional spectral flow cytometry and successive samples from four patients were profiled by scRNAseq (Figure 1A, Table S2, S3). Airway supernatants and blood plasma from early and late time points were also assayed for cytokines and chemokines (Figure 1A, Table S2).

\section{Distinct immune cell composition in airway and blood of COVID-19 patients}



through ficoll (see methods), stained using a 34 marker panel containing antibodies specific for major lineage determinants and markers for differentiation, tissue residence, activation, and

4 function (see methods), and analyzed by spectral flow cytometry (gating strategy for mononuclear cells shown in Figure S1). Principal component analysis (PCA) of mean marker expression for each sample showed distinct clustering of airway and blood samples by site, but not by outcome or by patient (Figure 1B, Table S4). Computational analysis of flow cytometry data visualized by uniform manifold approximation and projection (UMAP) embedding (see methods) showed distinct separation of the major lineages into monocytes/macrophages, $\mathrm{CD}^{+} \mathrm{T}$ cells, CD ${ }^{+} \mathrm{T}$ cells, B cells, and innate lymphoid cells (predominantly NK cells) for all samples

11 (Figure 1C, Figure S2A). Compiled data for each timepoint revealed distinct immune cell 12 composition in airway compared to blood (Figure 1D). Airway samples had predominant 13 frequencies of monocytes/macrophages (40-90\%), lower $\mathrm{T}$ cell frequencies, and very low-to14 negligible frequencies of B cells and ILCs, while blood contained higher lymphocyte frequencies with monocytes comprising $\sim 50 \%$ of all non-neutrophil leukocytes (Figure 1D). Similar immune 16 cell compositions were confirmed by scRNAseq analysis of airway and blood from four 17 individuals (Figure S2B). These results show distinct immune cell profiles in airway compared to 18 blood across all patients and timepoints analyzed.

We investigated whether the airway or blood immune cell composition differentiated

20 between patients or correlated with overall survival. Hierarchical clustering of aggregated 21 samples from each individual revealed two major patterns of immune cell composition in the 22 airways; one pattern showing a predominance of monocytes/macrophages, while the second 23 pattern had higher frequencies of $\mathrm{CD}^{+} \mathrm{T}$ cells, B cells, and ILCs compared to the first (Figure 1E 
1 left). However, neither pattern significantly correlated to outcome as patients who survived or

2 succumbed were represented in both groups (Figure 1E, left). Hierarchical clustering of blood

3 immune cell data revealed multiple clusters with different numbers of patients in each with no

4 clear distinction in patterns or by patient outcome (Figure 1E, right). The longitudinal profiles of

5 immune cell composition for individual patient samples also showed distinct composition in

6 airways, which did not correspond to blood either in frequency or in changes over time (Figure

7 1F, Figure S3A). However, examination of specific lineages showed significant associations with

8 outcome and correlation with age. Notably, there was a significant decrease in frequencies of

9 airway monocytes/macrophages and an increase in airway $\mathrm{CD} 4^{+} \mathrm{T}$ cells in patients who survived

10 the disease versus those who succumbed (Figure 1G, left, Figure S3B), while the frequency of

11 the corresponding blood immune cell subsets did not significantly differ between patients based

12 on outcome, nor did they correlate with age (Figure 1G, right, Figure S3B). Accordingly,

13 clustering the longitudinal patterns of cell type frequencies using K-means further suggests that

14 airway immune cell trajectories are a better indicator of clinical outcome than their blood

15 counterparts (Figure S3C). Together, these results show that airways exhibit an immune cell

16 composition distinct from blood, and that the dynamics of airway $\mathrm{T}$ cells and

17 monocyte/macrophages are significantly associated with outcome, suggesting key roles for these

18 cell types in disease pathogenesis.

\section{Tissue resident memory $\mathbf{T}$ cells are the major $\mathbf{T}$ cell subset in airways}

The subset composition and transcriptional profile of airway $\mathrm{T}$ cells in comparison to

22 those in blood was further examined through high-dimensional, single cell approaches. Multiple

23 markers of $\mathrm{T}$ cell differentiation were used to distinguish naïve and memory populations 
1 (CD45RA, CCR7, CD95, CD27), activation (HLA-DR, PD-1), functional subsets (FOXP3/CD25

2 for Tregs, CXCR5/PD-1 for Tfh-like, TCRGD for $\gamma \delta$ T cells), specific states of senescence or

3 terminal differentiation (CD57, KLRG1), and tissue residence (CD69, CD103). We used UMAP

4 embedding to visualize expression of these multiple markers by airway and blood $\mathrm{T}$ cells,

5 showing increased expression of CD69, CD103, PD-1, and HLA-DR in the airways and

6 increased CCR7, CD45RA, and CD127 expression in the blood (Figure S4A and S4B).

7 Phenograph clustering based on marker expression by $\mathrm{CD}^{+}$and $\mathrm{CD}^{+} \mathrm{T}$ cells yielded 27

8 clusters, which were coalesced into 15 clusters denoting biological subsets or

9 functional/activation states in airway and blood (Figure 2A, 2B).

There were significant qualitative and quantitative differences in $\mathrm{T}$ cell subset composition and activation state between airway and blood. In particular, airway contained CD4 ${ }^{+}$ and $\mathrm{CD}^{+}{ }^{\mathrm{TRM}}$ cells $\left(\mathrm{CD} 69^{+} \mathrm{CD}_{103^{+-}}\right)$along with activated TRM subsets expressing elevated

13 levels of HLA-DR and PD-1, and reduced levels of CD127 compared to non-activated TRM

14 (Figure 2A, 2B). TRM cells, regardless of activation state, were largely confined to the airways 15 and not significantly present in blood (Figure 2B, 2C), consistent with virus-responding $\mathrm{T}$ cells 16 located at the site of infection. Innate-like $\gamma \delta$ cells were also present in higher frequencies in 17 airways compared to blood (Figure 2C). Circulating TEM cells (CD69-CD103`) were present in both sites, with non-activated $\mathrm{CD}^{+}$TEM enriched in the blood (Figure 2B, 2C). Blood also 19 contained higher frequencies of naïve $\mathrm{CD} 4^{+}$and $\mathrm{CD} 8^{+} \mathrm{T}$ cells, $\mathrm{CD} 4^{+} \mathrm{TCM}$ cells (Figure $2 \mathrm{~B}, 2 \mathrm{C}$ ). Between patients, there was variability in the proportions of the major subsets represented; most

21 patients (9/13) had predominant CD8 ${ }^{+}$TRM in airways, while 3/13 patients had higher 22 frequencies of $\mathrm{CD} 4^{+} \mathrm{TRM}$ in airways (Figure 2D). Together, these analyses indicate that both TRM and activated memory T cells (TRM and TEM) exhibit biased distribution in favor of the 
1 airways and not blood, and that the subset composition and activation states of blood $\mathrm{T}$ cells does

2 reflect the dynamics in airways.

Consistent with the flow cytometry results, analysis of $\mathrm{T}$ cells by scRNA-seq revealed distinct transcriptional profiles expressed by airway compared to blood T cells. TRM signature genes CXCR6 and ITGAl were uniquely expressed by airway T cells (Figure 2E, F, Table S5),

6 consistent with previous scRNA-seq analysis of human TRM cells in lung and other sites

7 (Snyder et al., 2019; Szabo et al., 2019). Naïve and TCM cells distinguished by SELL expression

8 were highly enriched in blood, while CCL5 expression indicating TEM cells were found in both

9 sites (Figure 2F). Identification of the top differentially expressed genes between airway and blood revealed that $\mathrm{T}$ cells from the airway exhibit a gene signature associated with TRM and

11 tissue T cells (Kumar et al., 2017; Szabo et al., 2019), including upregulated expression of 12 CXCR6, ITGA1, PDCD1, LGALS, LAG3, and RBPJ compared to blood T cells (Figure 2E, F, 13 Table S5). Airway T cells also showed upregulated expression of genes encoding key cytokines 14 and chemokines, including IFNG,CCL2, and CCL4 (Figure 2E, F), consistent with an activated 15 and pro-inflammatory state. By contrast, blood $\mathrm{T}$ cells exhibited higher expression of genes 16 associated with quiescence (TCF7, LEF1) (Choi et al., 2015) and lymphoid homing (SELL)

17 compared to airway $\mathrm{T}$ cells (Figure 2E,F). These scRNA-seq results demonstrate 18 compartmentalization of activated TRM populations in the airway of severe COVID-19 in the 19 context of relatively quiescent blood $\mathrm{T}$ cells, suggesting that the protective $\mathrm{T}$ cell response is 20 targeted to the respiratory environment. 
The vast majority of $\mathrm{B}$ cells profiled in COVID-19 patients were from the blood;

2 however, there was a small but detectable population in the airways (Figure 1C, 1D). Comparing

$3 \quad$ B cell profiles by flow cytometry analysis revealed differential expression of key B cell markers

4 delineating specific B cells subsets in the airways and blood (Figure S5A, S5B). In particular,

5 airway B cells exhibited increased expression of CD69, a marker expressed by human tissue

6 resident B cells (Weisel et al., 2020), and activation markers CD86 and CD95 (Figure S5A,

7 S5B). Phenograph clustering further delineated subsets of activated and tissue-resident B cells

8 present in airways, while blood contained higher frequencies of $\mathrm{CXCR}^{+}$and naïve $\mathrm{B}$ cells

9 (Figure S5C-E). These results indicate compartmentalization of specific B cell subsets in airway, providing further support for spatial segregation of adaptive immunity.

\section{Airway monocytes/macrophages exhibit activation and inflammatory profiles}

We applied similar high-dimensional flow cytometry and scRNA-seq analysis to the monocyte/macrophage populations in paired airway and blood samples from COVID-19 patients. Phenotypic profiling of airway and blood samples defined a major monocyte/macrophage population (see Figure 1), which largely segregated by site (Figure 3A).

17 Expression of markers HLA-DR, CD11c, and CD16 distinguished airway from blood 18 monocyte/macrophages, while those in blood expressed higher levels of CD14 and CD163

19 (Figure 3A, B). There was no difference in the relative expression of CD64 and CD86 between 20 airway and blood monocyte/macrophages (Figure 3B). Phenograph clustering of 21 monocytes/macrophages identified 20 clusters, which were coalesced into 6 clusters classified by 22 activation (HLA-DR and CD86) and major monocyte subsets: classical, intermediate, and non23 classical (Kapellos et al., 2019) (Figure 3C). Non-classical monocytes/macrophages (both non- 
1 activated and activated) and activated classical monocytes/macrophages were enriched in the

2 airway (Figure 3D, E). By contrast, classical and intermediate monocytes/macrophages without

3 activation markers were increased in the blood (Figure 3D, E). These data indicated increased

4 activation of monocyte/macrophage lineages in the airway compared to blood.

We further investigated the subset delineation, differentiation, and functional state of

6 monocyte/macrophages by scRNA-seq. Transcriptionally, airway monocyte/macrophages

7 exhibited certain shared and distinct gene expression patterns compared to blood counterparts,

8 which were consistent across individuals (Figure 4A, Table S6). There was comparable

9 expression of lineage-defining genes, including CD14, FCGR3A (CD16), CD68, and CD163, for

monocyte/macrophages in the airway and blood. However, several genes distinguished the two

11 sites, including airway-specific expression of tissue macrophage markers $M A R C O$ and $M R C 2$

12 (CD206) (Bharat et al., 2016) and the integrin ITGAV (encoding the vitronectin receptor for

13 tissue matrix interactions), while blood counterparts expressed higher levels of transcripts for

14 chemokine and homing/egress receptors (CX3CR1, CCR2, SELL, S1PR4) (Figure 4A). For genes

15 associated with myeloid cell function, airway monocytes/macrophages expressed highly elevated

16 levels of transcripts for pro-inflammatory mediators compared to blood, including chemokines

17 for recruitment of monocyte/macrophages (CCL2, CCL3, CCLA), lymphocytes (CCL18, CCL20,

$18 C C L 23)$, and neutrophils (CXCL3,CXCL5), complement components $(C 3, C 1 Q B, C 1 Q C)$, and

Kheradmand, 2017) (Figure 4A). Together, these results demonstrate distinct tissue and

21 functional profiles of airway monocyte/macrophages compared to those in the blood.

22 Importantly, airway monocytes/macrophages persist in a highly inflammatory state with elevated 
1 expression of chemotactic mediators, suggesting potential roles for lung macrophages in

2 recruiting immune cells to the lung in severe COVID-19.

Interferon (IFN)-regulated genes are associated with innate anti-viral immunity and may

4 be dysregulated in COVID-19 (Hadjadj et al., 2020). Accordingly, we found negligible

(Figure 4B) or epithelial cells (Figure S6), consistent with the lack of SARS-CoV-2 viral sequences (see methods) in scRNA-seq data from 4 patients. However, transcripts associated detected in both the airway and blood monocyte/macrophages (Figure 4B), as well as airway epithelial and T cells (Figure S6), suggesting a persisting anti-viral state in these cells. This expression of IFN-regulated genes may be propagated by IFNG expressed by airway T cells

12 (Figure 2, S6). Together these results indicate that the principal innate immune function of 13 myeloid-derived cells in severe COVID-19 is production of pro-inflammatory mediators by airway monocyte/macrophages.

\section{Compartmentalized production of cytokines and chemokines in airway and blood}

We further assessed inflammation in both sites by direct examination of cytokine and chemokine content in airway supernatants and plasma samples from an early (day 1) and later (days 3-7) timepoint for each patient (Table S2). We used a microfluidic chip multiplexed

22 significant differences in the cytokine and chemokine protein content in the airway compared to 23 plasma, but no significant differences between the two timepoints within a site (Figure 5A, 
medRxiv preprint doi: https://doi.org/10.1101/2020.10.15.20208041; this version posted October 19, 2020. The copyright holder for this preprint (which was not certified by peer review) is the author/funder, who has granted medRxiv a license to display the preprint in perpetuity.

1 Figure S7A,B). Analytes significantly elevated in airways compared to blood include monocyte/macrophage chemoattractants MCP-1 (CCL2), MIP-1 $\alpha$ (CCL3), and MIP1 $\beta$ (CCL4)

3 in all samples, as well as granzyme B, IL-7, and TNF- $\beta$ associated with T cells and homeostasis

4 (Figure 5A, 5B, Figure S7B). By contrast, in the blood, MCP-1 (CCL2), MIP-1 $\alpha$ (CCL3), granzyme B, TNF- $\beta$, and IL-7 were undetectable, while MIP-1 $\beta$ (CCL4) was present at variable

6 levels across patients (Figure 5A, B). Both blood and airways contained low and/or variable

7 levels of molecules associated with T cell effector function (perforin, IFN- $\gamma$, IL-17, and IL-2),

8 additional innate cytokines (IL-6 and IL-8), and TGF- $\beta$, while none of the analytes measured

9 were uniquely expressed by blood and not found in airways (Figure 5A, 5B, Figure S7B). Together, these results show compartmentalized production of pro-inflammatory chemokines

11 and cytokines in the airway with a subset of these detected in blood, suggesting that systemic cytokines may derive from inflammatory processes originating at the infection site.

To define the cellular origin of the chemokines and cytokines detected in each 14 compartment, we analyzed transcript expression for each of the analytes from Figure 5B by scRNA-seq. Overall, transcript expression of prominent cytokines/chemokines largely correlated to the protein data; airway myeloid cells expressed high levels of CCL2, CCL3 and CCLA transcripts corresponding to the high levels of the respective proteins in airways, while blood myeloid cells expressed lower or undetectable levels of these transcripts (Figure 5C). Airway and blood myeloid cells also expressed $C X C L 8$ and $T G F B 1$, consistent with the protein data (Figure 5C). In the airways, $\mathrm{T}$ cells expressed GZMB, CXCL8, CCLA, PRF, IFNG, and TGFB1

21 transcripts, which were expressed by blood $\mathrm{T}$ cells at lower or variable levels (Figure 5C).

22 Airway epithelial cells expressed predominantly CXCL8 transcripts, as well as lower levels of 23 transcripts for IL-7 and several chemokines (Figure 5C). Overall, these results demonstrate 
medRxiv preprint doi: https://doi.org/10.1101/2020.10.15.20208041; this version posted October 19, 2020. The copyright holder for this preprint (which was not certified by peer review) is the author/funder, who has granted medRxiv a license to display the preprint in perpetuity.

All rights reserved. No reuse allowed without permission.

1 compartmentalized secretion of monocyte/macrophage-derived chemokines and inflammatory

2 mediators in the airways with potential roles for recruiting immune cells to the lung that may

3 contribute to lung inflammation and tissue damage.

4

\section{COVID-19-induced features of airway and blood immune cells}

To assess COVID-19-related alterations in airway and blood immune cells that could potentially contribute to disease pathogenesis, we obtained baseline controls of blood from

8 uninfected, healthy adults, and airway washes from lungs of SARS-CoV-2-negative organ 9 donors as done previously (Snyder et al., 2019). High-dimensional flow cytometry analysis of control healthy blood (HB) and airway (HA) samples (Table S7), in conjunction with the

11 COVID-19 patient samples from Figure 1 (COVID-19 blood (CB); COVID-19 airway (CA))

12 revealed non-overlapping features of COVID-19 and healthy samples for all lineages and 13 particularly within $\mathrm{T}$ cells and monocyte/macrophages (Figure 6A, left). Overall immune cell composition and T:monocyte/macrophage cell ratio were similar in healthy and COVID-19 airway samples; however, a dramatic increase in circulating monocyte frequency resulting in a reduced T: monocyte/macrophage ratio was observed in COVID-19 blood relative to healthy

17 controls (Figure 6A, middle and right). By PCA, airway and blood samples were distinct, 18 irrespective of disease; however, healthy and COVID-19 airway samples were intermixed, while 19 healthy blood samples clustered separately from COVID-19 blood samples (Figure 6B). These 20 findings indicate that COVID-19-specific alterations in immune cell composition are manifested 21 more dramatically in blood than in airways.

To more closely examine site-specific differences between immune cells in healthy and COVID-19 individuals, we analyzed $\mathrm{T}$ cell and monocyte/macrophage populations separately. 
1 UMAP embeddings of $\mathrm{T}$ cells from blood and airway showed compartmentalized profiles for

2 both healthy and COVID-19 samples (Figure 6C, left). We calculated a Minkowski Distance

3 (MD; see methods) to quantify the similarity in $\mathrm{T}$ cell populations across conditions and sites,

4 with higher values denoting greater similarity. T cell populations within each site were similar in

5 healthy and COVID-19 samples (HB v. CB MD =0.77; HA v. CA MD =0.74), whereas T cell

6 populations in the two sites were more distinct (HA v. $\mathrm{HB} \mathrm{MD}=0.39, \mathrm{CA}$ v. $\mathrm{CB} \mathrm{MD}=0.57$ )

7 (Figure 6C). Comparing $\mathrm{T}$ cells in healthy and COVID-19 samples, there were increased

8 frequencies of $\mathrm{CD}_{6} 9^{+} \mathrm{CD} 103^{+} \mathrm{TRM}$ and $\mathrm{T}$ cells expressing activation markers HLA-DR and PD-

91 in the airways of COVID-19 patients compared to uninfected individuals; these markers were not expressed significantly by blood T cells in COVID-19 nor in healthy controls (Figure 6D).

11 The compartmentalized activation of T cells in airways in COVID-19 provides further evidence

12 for dynamic $\mathrm{T}$ cell immunity at the infection site.

For monocytes/macrophages, UMAP embeddings revealed compartmentalized profiles between healthy airway and blood, but considerable overlap of monocyte/macrophage profiles between COVID-19 airway and blood (Figure 6E). Accordingly, Minkowski distance calculations confirmed that healthy airway and blood monocyte/macrophage subsets were distinct $(\mathrm{MD}=0.47)$, while in COVID-19 patients airway and blood myeloid cell profiles were more similar $(\mathrm{MD}=0.72$ ) (Figure 6E, right). Specifically, CD163, a scavenger receptor typically expressed by tissue macrophages and monocytes in response to inflammation (Buechler et al., 2000), was expressed in control airway macrophages and not by blood monocytes; however, in

21 COVID-19 samples, the proportion of monocytes/macrophages expressing high levels of CD163

$22\left(\mathrm{CD} 163^{\mathrm{hi}}\right)$ was similar in both sites (Figure 6F). Moreover, monocytes in healthy blood samples 
1 significantly reduced proportions of HLA-DR ${ }^{\text {hi }}$ and CD86 ${ }^{\text {hi }}$ cells (Figure 6F), consistent with

2 recent findings regarding blood monocyte profiles in severe COVID-19 and suggestive of an

3 immature phenotype (Schulte-Schrepping et al., 2020). Taken together, these results indicate

4 profound alterations in blood monocytes in COVID-19, which also share similar features with

5 airway macrophages, suggesting that airway resident myeloid cells in severe COVID-19 may

6 derive, in part, from these circulating precursors and that interactions between airway and blood

7 myeloid cells may contribute to disease pathology.

\section{Accumulation of $\mathrm{CD} 163^{+}$cells in the lungs of severe COVID-19 patients}

We hypothesized that the production of monocyte-chemoattractant chemokines by airway

monocyte/macrophages along with the elevated levels of $\mathrm{CD}_{163}{ }^{+}$monocytes in COVID-19 blood may result in their dysregulated infiltration into the lung. We therefore examined immune cells in lung autopsy samples from COVID-19 patients with diffuse alveolar damage, the main pathological finding associated with COVID-19 ARDS (De Michele et al., 2020), relative to lungs from uninfected, deceased organ donor controls (Carpenter et al., 2018) (Table S7). In the airways of uninfected lungs, T cells were clustered around the airway epithelium, while CD163 monocytes/macrophages were dispersed in the parenchyma (Figure 7A, top left). In the lungs of

17 individuals who succumbed to COVID-19 ARDS, there was a marked and dramatic increase in

$18 \mathrm{CD}_{163^{+}}$monocytes/macrophages and damaged airway epithelium that was partially denuded and sloughing off into the lumen (Figure 7A, top right). In particular, CD163

20 monocytes/macrophages aggregated in the alveolar spaces of COVID-19 infected lungs and not

21 in controls, suggesting their participation in lung damage in COVID-19. Quantitative analysis of 22 the lung imaging data showed significant increases in the frequency and density of CD $163^{+}$ 
medRxiv preprint doi: https://doi.org/10.1101/2020.10.15.20208041; this version posted October 19, 2020. The copyright holder for this preprint (which was not certified by peer review) is the author/funder, who has granted medRxiv a license to display the preprint in perpetuity.

All rights reserved. No reuse allowed without permission.

1 similarly increased (Figure 7B). We assessed expression of genes associated with cell cycle or

2 proliferation (Ki67, TOP2A, UBE2C) in monocyte/macrophage populations in the airway or

3 blood by scRNA-seq, revealing no significant expression of these markers (Figure 7C). Together

4 with the high-dimensional analysis of airway immune cells, these findings implicate the

5 recruitment of immature monocytes from the periphery into the lung, where they subsequently

6 become highly pro-inflammatory and drive the pathogenesis of severe COVID-19. 
medRxiv preprint doi: https://doi.org/10.1101/2020.10.15.20208041; this version posted October 19, 2020. The copyright holder for this preprint (which was not certified by peer review) is the author/funder, who has granted medRxiv a license to display the preprint in perpetuity.

All rights reserved. No reuse allowed without permission.

\section{DISCUSSION}

During the SARS-CoV-2 pandemic, restoration of normal life is impeded first and foremost by the most severe COVID-19 cases, including debilitating ARDS and its high mortality. Numerous studies have now identified characteristic features of innate and adaptive immunity to SARS-CoV-2 infection that are detectable in blood (Kuri-Cervantes et al., 2020; Laing et al., 2020; Lucas et al., 2020; Mathew et al., 2020; Moderbacher et al., 2020; SchulteSchrepping et al., 2020); however, the initiation, function, and establishment of immune responses for respiratory viruses occur in the lung and respiratory tract. Several studies have separately assessed cellular composition within the respiratory environment in bronchiolar lavage samples and lung autopsies (Damiani et al., 2020; Liao et al., 2020; Veras et al., 2020). Characterizing respiratory immune responses in situ in the context of circulating immune cell populations is needed to dissect mechanisms of disease pathogenesis to combat this pandemic.

In this study, we obtained paired respiratory and blood samples from patients with severe COVID-19 longitudinally during the course of intensive care hospitalization. We employed high dimensional profiling by spectral flow cytometry and scRNA-seq as well as multiplex cytokine quantification and immunofluorescence imaging to characterize airway and systemic immune responses and their interactions, revealing key insights into disease pathogenesis. Importantly, we found that innate and adaptive immune responses in severe COVID-19 predominate in the respiratory tract and are qualitatively and quantitatively distinct from immune dynamics in the blood. The most striking differences in immune cells between airways and blood were identified within both $\mathrm{T}$ cell and monocyte/macrophage populations. Moreover, increased frequencies of $\mathrm{T}$ cells and decreased macrophage/monocyte frequencies exclusively in the airways correlate with 
1 better outcome and younger age, further indicating key roles for these cells at the infection site in

2 disease pathogenesis.

T cells in COVID-19 airways were predominately TRM, most of which exhibited features of activation, including surface phenotypes (HLA-DR ${ }^{\text {hi }}$ PD- $1{ }^{\text {hi }}$ CD $127^{\text {lo }}$ ) and upregulated 5 expression of transcripts for effector molecules such as perforin, GZMB and IFNG. This was not the case in the blood of COVID-19 patients, which lacked TRM and activated T cell profiles.

7 Furthermore, activated TRM were detected specifically in airways of COVID-19 patients and not 8 in airway washes of organ donor controls, indicating a virus-directed response, although 9 insufficient $\mathrm{T}$ cell numbers in airways precluded direct measurement of SARS-CoV-2-specific T cells. In mouse influenza infection, the presence of activated lung TRM in situ to influenza infection correlates with virus-specific responses (Paik and Farber, 2020; Turner et al., 2014),

12 further supporting that in situ activation is a surrogate for anti-viral responses. In human SARS-

13 CoV-2 infection, blood may serve as a consistent and reliable indicator for detection of SARS-

14 CoV-2-specific T cells and the establishment of adaptive immune memory (Grifoni et al., 2020;

15 Moderbacher et al., 2020; Weiskopf et al., 2020). However, our results suggest that measuring global $\mathrm{T}$ cell activation markers in the periphery, as done in recent studies (Mathew et al., 2020;

17 Takahashi et al., 2020), may not provide an accurate assessment of the virus-targeted immune response in situ during active disease. 
1 inflammatory profile, excessive levels of MCP-1/CCL2, MIP-1 $\alpha / C C L 3$, and MIP-1 $\beta / C C L 4$

2 protein were detected in the airways, but not in blood, further supporting a role of airway

3 macrophages in initiating and perpetuating the inflammatory responses in severe COVID-19.

4 This phenotypic and functional profile of COVID-19 airway monocytes/macrophages shares

5 features with human macrophages in ARDS due to non-infectious causes, including the

6 production of CCL2 and CXCL8, as well as induction of MMPs and complement (Aggarwal et

7 al., 2014; Morrell et al., 2019). In ARDS, CCL2-expressing airway macrophages recruit

8 inflammatory monocytes expressing the CCL2 binding receptor CCR2, which contribute to lung

9 damage; airway macrophages can subsequently facilitate repair through TGF- $\beta$ production

10 (Aggarwal et al., 2014). Our results indicate that COVID-ARDS shares some key features with

ARDS resulting from other infectious or non-infectious causes.

Our coordinate analysis of airway and blood myeloid cells and soluble mediators suggest an analogous role for airway macrophages driving lung damage in COVID-19 ARDS through express increased levels of CCR 2 transcripts and aberrant CD $163^{+} \mathrm{HLA}^{-D R}{ }^{\mathrm{lo}} / \mathrm{CD} 86^{\mathrm{lo}}$ phenotypes compared to healthy blood monocytes. Reduced HLA-DR expression indicative of immature monocytes has been identified in blood myeloid cells in severe COVID-19 (Schulte-Schrepping 18 et al., 2020; Silvin et al., 2020) and may derive from inflammation-induced mobilization of immature monocytes from the bone marrow, termed emergency myelopoiesis (Schultze et al., 2019; Shi et al., 2011; Venet et al., 2020). While a cytokine storm marked by elevated levels of

21 serum cytokines is implicated in pathogenesis of severe COVID-19 and emergency myelopoiesis

22 (Chau et al., 2020; Copaescu et al., 2020; Lucas et al., 2020; Schulte-Schrepping et al., 2020), our results show that inflammatory cytokines detected in the blood lacked CCL2 and other 
medRxiv preprint doi: https://doi.org/10.1101/2020.10.15.20208041; this version posted October 19, 2020. The copyright holder for this preprint (which was not certified by peer review) is the author/funder, who has granted medRxiv a license to display the preprint in perpetuity.

All rights reserved. No reuse allowed without permission.

1 chemokines, which direct recruitment of multiple immune cell types. Our findings rather suggest

2 that pro-inflammatory cytokines emanating from the respiratory tract recruit circulating

3 inflammatory monocytes to the lungs and perpetuate lung damage. Immunofluorescence imaging

4 of lungs from severe COVID-19 patients shows a striking increase in CD163-expressing

5 monocytes/macrophages within the damaged lung tissue that lack proliferative signatures and

6 therefore likely derive from recruitment. These cells specifically accumulate in the alveolar

7 spaces of the lungs, a key site for blood gas exchange, suggesting their involvement in diffuse

8 alveolar damage commonly seen in COVID-19 pathology (De Michele et al., 2020).

Our results defining airway immune responses in COVID-19 and their relation to the corresponding immune reactants in blood have profound implications for treating and preventing with cytokine blockade, have shown variable efficacy in severe COVID-19 (Della-Torre et al., through CCR2 antagonists or other airway-specific mediators may be more effective in reducing lung damage or even promoting recovery from ARDS in severe COVID-19. A similar role for CCL2-mediated monocyte recruitment in lung pathology was demonstrated in mouse models of

17 influenza infection (Lin et al., 2008; Lin et al., 2011), suggesting a generalized mechanism for respiratory virus-induced lung injury. Because our scRNA-seq analysis showed that the elevated 19 airway mediators derive chiefly from the lung macrophages, treatments which regulate these cells may also mitigate the clinical course of disease. important consideration for vaccine design. In mouse models, intranasal administration of the 
1 live-attenuated influenza vaccine or bacterial-based vaccines can promote establishment of lung

2 TRM that mediate protective immunity to pathogen challenge (Allen et al., 2018; Zens et al.,

3 2016). Intravenous administration of the BCG vaccine to non-human primates was recently

4 shown to generate substantial populations of lung TRM, which correlated strongly with

5 protection from tuberculosis (Darrah et al., 2020). The current SARS-CoV-2 vaccines in phase

6 III trials target generation of neutralizing antibodies and are robust strategies for establishing

7 sterilizing immunity (Jeyanathan et al., 2020); however, respiratory targeting could be

8 considered for individuals who are unable to develop effective antibody responses. These cohorts

9 may include the immunocompromised or the elderly, or this strategy could be used as a booster

10 for those at risk for infection due to frequent interactions with others through their living or work

11 situations. Indeed, a recent pre-clinical study demonstrated that intranasal administration of a

12 recombinant SARS-CoV-2 vaccine promoted lung TRM generation and protection from viral

13 challenge in a mouse model (Hassan et al., 2020).

In summary, our study provides a dynamic view of ongoing respiratory immunity in

15 severe COVID-19, revealing compartmentalization of protective and pathogenic immune

16 responses in the lung. These findings have important implications for how we monitor, treat and

17 protect from this pandemic and future infectious challenges to the respiratory tract. 
medRxiv preprint doi: https://doi.org/10.1101/2020.10.15.20208041; this version posted October 19, 2020. The copyright holder for this preprint (which was not certified by peer review) is the author/funder, who has granted medRxiv a license to display the preprint in perpetuity.

All rights reserved. No reuse allowed without permission.

\section{Acknowledgements}

2 We wish to express our gratitude to the Medical ICU nurse champions, Cora Garcellano, Tenzin

3 Drukdak, Harriet Avila Raymundo, Lori Wagner, and Ricky Lee, who led the efforts to obtain

4 patient samples for the adult ARDS patients, to Evelyn Hernandez and Lorena Gomez for their

5 roles as clinical coordinators, and to the nurses and clinical staff in the Pediatric Intensive Care

6 Unit of MSCHONY. We acknowledge the dedication, commitment, and sacrifice of the other

7 nurses, providers, and personnel who helped care for these patients during the COVID-19 crisis.

8 We acknowledge the suffering and loss of our COVID-19 patients and of their families and our

9 community. We also gratefully acknowledge the generosity of the donor families and the

exceptional efforts of LiveOnNY transplant coordinators and staff for the donor lungs.

11 This work was supported by NIH grants AI128949 and AI06697 awarded to D.L.F., a Chan

12 Zuckerberg Initiative COVID-19 grant to D.L.F. and P.A.Sims, and an R01AI093870 awarded to

13 A.J.Y. P.D. was supported by a CRI-Irvington Postdoctoral Fellowship and P.A.S. by a Canadian

14 Institutes of Health Research Fellowship. T.J.C. is supported by NIH K23 A1141686 and S.P.W.

15 is supported by NIH K08 DK122130. Research reported in this publication was performed in the

16 Human Immune Monitoring Core, the Columbia Single Cell Analysis Core, and the Sulzberger

17 Columbia Genome Center, which are supported by an NCI cancer center support grant

P30CA013696. The content is solely the responsibility of the authors and does not necessarily

19 represent the official views of the National Institutes of Health. We thank Eldad Hod for use of

20 his laboratory for sample processing, and Carly Ziegler and Dr. Alex Shalek of MIT for sharing

21 their merged human / SARS-CoV-2 genome and transcriptome annotation.

\section{Author Contributions}


1 P.A.Sz., S.W., J.G., P.D. processed samples, designed and optimized high-dimensional flow

2 cytometry panels, analyzed data, made figures, and wrote the manuscript. P.A.Sz. and S.W.

3 processed samples for scRNAseq profiling and encapsulation using 10X Chromium; I.K.

4 prepared and sequenced the 10X libraries. P.D. designed the Python pipeline for flow cytometry

5 data. M.B. monitored and consented ICU patients, oversaw clinical data analysis , and collected

6 samples. T.C. obtained and maintained IRB protocols, consented patients, and processed

7 samples. M.M.L.P., R.M., E.I., M.C. obtained and processed patient samples. S.E.M., C.P., and

8 A.JY. statistically analyzed longitudinal data; J.D.-P. captured and analyzed patient data; J.Z.,

9 M.S. S.M. performed cytokine analysis of airway supernatants and blood plasma; S.P.W.

10 planned, designed, and analyzed lung autopsy imaging experiments; A.S. provided lung autopsy

11 samples and associated data; A.K. performed immunohistochemistry of lung autopsies. P.A.Sims

12 planned scNAseq experiments, analyzed data, and, wrote and edited manuscript. D.L.F. oversaw

13 compliance, planned experiments, coordinated sample acquisition and data acquisition/analysis,

14 analyzed data, and wrote and edited the paper.

\section{Declaration of Interests}

16 J.Z., M.S. and S.M. have competing interests with IsoPlexis. The remaining authors declare no

17 competing interests. 
medRxiv preprint doi: https://doi.org/10.1101/2020.10.15.20208041; this version posted October 19, 2020. The copyright holder for this preprint (which was not certified by peer review) is the author/funder, who has granted medRxiv a license to display the preprint in perpetuity.

All rights reserved. No reuse allowed without permission.

\section{FIGURE LEGENDS}

\section{Figure 1. Distinct immune cell composition in airways compared to blood is associated with} outcome and age (A) Schematic diagram showing assays performed on COVID-19 patient airway and blood samples for this study. (B) Principal component analysis (PCA) of all COVID19 samples based on mean marker expression colored by site (left), outcome (middle) and by donor (right). (C) UMAP embedding of flow cytometry results from all airway and blood samples combined colored by major cell lineage (top panel), and separated by tissue site (bottom two panels). (D) Immune cell composition over time in airways and blood. Box plots show the frequency of each major cell lineage of $\mathrm{CD}^{+} 5^{+} \mathrm{CD} 6 \mathrm{~B}^{-}$cells in airway (left) and blood (right) samples collected longitudinally for each sample day. Color of boxes corresponds to lineage and each dot is an individual patient sample. (E) Hierarchical clustering of airway (left) and blood (right) samples based on average lineage frequency across all time points for each donor-site group. Heatmaps are colored by row normalized value for each sample. (F) Line plots showing frequency of major lineages of total $\mathrm{CD} 45^{+} \mathrm{CD}^{-} 6 \mathrm{~B}^{-}$cells in airway (top row) and blood (bottom row) samples collected longitudinally for representative donors. (G) Association of monocyte/macrophage and $\mathrm{T}$ cell frequencies in airway (left) and blood (right) with outcome (deceased or survived) and correlation with age. Statistical significance was calculated using Mann-Whitney U-tests (box-plots) or Pearson correlations (scatter plots) and indicated by ***, p $\leq 0.001 ; * *, \mathrm{p} \leq 0.01 ; *, \mathrm{p} \leq 0.05$

\section{Figure 2. Airway T cells in COVID-19 are dominated by TRM and activated phenotypes.}

(A) Heatmap displaying expression of markers within phenograph-generated, hierarchical T cell clusters. The 27 phenograph clusters were collapsed into 15 definable cell subsets indicated at bottom. Heatmap data are colored by row normalized value for each sample. (B) UMAP 
1 embedding of $15 \mathrm{~T}$ cell subsets in the airway (upper) and blood (lower) with labels denoting the

2 specific subset as defined in A. (C) T cell subset frequencies in airway compared to blood

3 samples. Boxplots showing frequency of the indicated $\mathrm{T}$ cell subset for each patient (average of

4 all time points collected) in the airway (blue) and blood (red). Statistical significance was

5 calculated using a paired T-tests and indicated by ***, $\mathrm{p} \leq 0.001 ; * *, \mathrm{p} \leq 0.01 ; *, \mathrm{p} \leq 0.05$. (D)

6 Frequencies of the major $\mathrm{T}$ cell subsets in airway and blood shown for each individual patient

7 and their outcome in airway (left) and blood (right) shown in a heat map. (only select subsets

8 shown) (E) Heatmap showing major differentially expressed genes in airway compared to blood

9 T cells by scRNA-seq from each individual patient and timepoint. Data are colored by row zscore for each sample. (F) Separate UMAP embeddings of gene expression by scRNA-seq from

11 total T cells obtained from airway and blood of paired samples from four patients. UMAP shows 12 airway (blue) and blood (red) origin of samples, patient, and indicated gene expression (based on $\log 2(\mathrm{CPM}+1))$.

Figure 3. Monocyte/macrophage lineage cells are activated in airway of COVID-19 patients (A) UMAP embedding of aggregated flow cytometry data obtain in Figure 1 showing expression of major myeloid markers in airway and blood. (B) Mean expression of each myeloid-associated marker within the airway (blue) or the blood (red) samples shown as boxplots with each dot expression of markers within phenograph-generated, hierarchical monocyte/macrophage clusters.

21 nomenclature - classical, intermediate and non-classical, and whether they were activated

22 (“Act."). Heatmap data are colored by row normalized value for each sample. (D) UMAP embedding of the different subsets colored as in $\mathrm{C}$ from airway and blood samples. (E) Boxplots 
medRxiv preprint doi: https://doi.org/10.1101/2020.10.15.20208041; this version posted October 19, 2020. The copyright holder for this preprint (which was not certified by peer review) is the author/funder, who has granted medRxiv a license to display the preprint in perpetuity.

All rights reserved. No reuse allowed without permission.

1 showing compiled frequency of each monocyte/macrophage subset displayed as an average of all

2 time points collected on a per donor basis. Statistical significance was calculated using a paired

$3 \quad$ T-test and indicated by ***, $\mathrm{p} \leq 0.001 ; * *, \mathrm{p} \leq 0.01 ; *, \mathrm{p} \leq 0.05$.

Figure 4. Airway contains tissue macrophages and monocytes with highly inflammatory

5 profiles compared to blood (A) Monocyte/macrophage profiles in airway and blood were analyzed by scRNAseq. Gene expression analysis of scRNAseq of subset-defining genes,

7 homing receptors and key inflammatory molecules for monocyte/macrophages in airway and blood from each patient sample (left). The heatmap shows genes that are not differentially expressed between airway and blood (CD14-FCGR3A) and genes are consistently differentially expressed (ITGAV-TREM2). UMAP embedding of total monocyte/macrophage cells obtained from airway (blue dots) and blood (red dots) compiled from four patient samples (right). (B) Expression levels of the IFN response genes between airway and blood (left). UMAP embedding displaying the expression levels of the IFN response genes in individual cells (right) displayed as $\log _{2}(\mathrm{CPM}+1)$.

Figure 5. COVID-19 airways contained highly elevated levels of myeloid and $\mathbf{T}$ cell-derived

17 (top) and plasma (bottom) compiled from 15 patients depicted in box plots showing $\log _{10}$ normalized cytokine expression profiles for an early and late time point (see methods). Each dot represents an individual data point. (B) Heatmap showing $\log _{10}(X+1) \mathrm{pg} / \mathrm{mL}$ cytokine levels averaged across both time points in airway (left) and blood plasma (right) samples for each donor. (C) Transcript levels for cytokine expression by major cell lineages identified in by

22 scRNA-seq for each patient samples indicated by color. Heatmap shows $\log _{2}(\operatorname{mean} \mathrm{CPM}+1)$ gene expression. 
medRxiv preprint doi: https://doi.org/10.1101/2020.10.15.20208041; this version posted October 19, 2020. The copyright holder for this preprint (which was not certified by peer review) is the author/funder, who has granted medRxiv a license to display the preprint in perpetuity.

All rights reserved. No reuse allowed without permission.

Figure 6. Defining COVID-19-associated immune responses relative to healthy blood and airway samples. Blood was obtained from healthy adults and airway samples from lungs of SARS-CoV-2-negative organ donors; immune cells were stained with the flow cytometry panel in Figure 1 and analyzed in conjunction with COVID-19 patient samples. (A) Comparison of major immune cell lineages in healthy ( $\mathrm{n}=6$ airway and 5 blood) and COVID-19 airway ( $\mathrm{n}=54)$ and blood ( $\mathrm{n}=54)$ samples. Left: UMAP embedding of samples colored by condition (healthy purple; COVID-19 - orange). Middle: Box plots showing the frequency of indicated immune cells from total $\mathrm{CD} 45^{+} \mathrm{CD} 6 \mathrm{~B}^{-}$cells for each site. Each dot is the average of all time points per patient/donor. Right: Ratio of T: monocyte/macrophage for each site and condition. (B) PCA of mean marker expression (average of each time point for COVID-19 samples) for COVID-19 airway (blue), healthy airway (yellow), COVID-19 blood (black) and healthy blood (red). (C) T cell compartmentalization in airways and blood in health and COVID-19. Left: UMAP embedding of the T cell expression data for COVID-19 and healthy controls across airway and blood (upper two panels). Right: Correlation heatmaps calculated using Minkowski distance (MD) measures (shown in heat maps as 1-MD) with higher values indicating greater similarity between two samples. HA - healthy airway, HB - healthy blood, CA - COVID-19 airway, CB COVID-19 blood. (D) Expression of T cell residency and activation markers in airway and blood of healthy and COVID-19 samples. Left: Contour plots showing mean expression of indicated markers within the airway (blue contours) and blood (red contours) by condition (healthy or COVID-19). Right: Boxplots show frequency of cells expressing indicated markers, for each sample. (E) Monocyte/macrophage compartmentalization in airways and blood in health and COVID-19. Left: UMAP embedding of the monocyte/macrophage compartment of COVID-19 and healthy controls across airway and blood (upper two panels). Lower panels indicate 
1 correlation heatmap as an average by condition and site (lower right panel). Minkowski distance

2 metric calculated as in D but for myeloid cells. HA - healthy airway, HB - healthy blood, CA -

3 COVID-19 airway, CB - COVID-19 blood. (F) Expression of monocyte/macrophage markers in

4 airway and blood. Left: Contour plots showing indicate mean expression of indicated markers by

5 monocyte/macrophages in airway (blue contours) and blood (red contours) samples by condition

6 (healthy or COVID). Right: Boxplots indicate percentage of cells within each condition and site

7 that were positive for specific markers, given as an average over all time points for COVID-19

8 samples. Statistical significance was calculated using a one-way ANOVA followed by a Tukey

$9 \quad$ HSD and indicated by ***, $\mathrm{p} \leq 0.001 ; * *, \mathrm{p} \leq 0.01 ; *, \mathrm{p} \leq 0.05$.

Figure 7. Lung pathology in COVID-19 shows extensive accumulation of $\mathrm{CD163}^{+}$cells donors and autopsy specimens from COVID-19 patients with diffuse alveolar damage were stained with indicated antibodies and analyzed using Vectra. Representative images show T cell (CD4, CD8), and monocyte/macrophages (CD163) staining in the lungs of uninfected controls (left) and COVID-19 patients (right). (B) Quantitation of $\mathrm{T}$ cell and monocyte/macrophage content in control $(n=2)$ and COVID-19 $(n=5)$ lungs as a frequency of total lung cells or density

17 (cells per $\mathrm{mm}^{2}$ cellular area) using InForm software. Statistical significance indicated by $* * *, \mathrm{p} \leq$ seq in monocyte/macrophages derived from airway and blood as in Figure 4. 
medRxiv preprint doi: https://doi.org/10.1101/2020.10.15.20208041; this version posted October 19, 2020. The copyright holder for this preprint (which was not certified by peer review) is the author/funder, who has granted medRxiv a license to display the preprint in perpetuity.

\section{Supplemental Figure Titles and Legends}

2 Figure S1. Gating strategy for flow cytometry analysis (A) FACS plots denoting the gating

3 strategy used for analysis of myeloid and lymphocyte populations using the Aurora flow

4 cytometry from complex populations in airway samples, with complementary gating for blood

5 cells. Total cells were initially gated on $\mathrm{CD}_{4} 5^{+}$cells versus time to eliminate non-hematopoietic

6 cells and debris; doublets were excluded followed by exclusion of neutrophils (FSC-A ${ }^{\text {hi }}$

$7 \mathrm{CD}_{66 b^{+}}$). Finally, dead cells were excluded by gating on CD45 and LIVE/DEAD blue. The

8 resulting populations contained the full complement of mononuclear immune cells used for

9 downstream analysis.

Figure S2. Expression of lineage defining markers determined by flow cytometry and scRNA-seq (A) UMAP embedding displaying expression of lineage-defining markers for the major immune cell subsets in combined airway and blood samples from 13 COVID-19 patients. (B) Heatmap of scRNA-seq data displaying gene expression of lineage defining markers for both the airway and blood across the four donors. Heatmap data are colored by $\log _{2}(\mathrm{CPM}+1) / \max$ values for each sample.

Figure S3. Major immune cell lineages over time in COVID-19 patients. (A) Individual

17 patient data displaying the proportion of each major immune cell lineage over the time course of sample collection. D - deceased, S - survived. (B) Classification performance of longitudinal Kmeans clustering for different combinations of immune cell trajectories. The percentage of donor outcomes that were successfully classified as deceased or survived is shown when all subsets,

21 only myeloid and T cells, only myeloid, or only $\mathrm{T}$ cells were used for clustering. Colors denote

22 whether airway, blood, or both airway and blood trajectories were included. (C) Association of 
medRxiv preprint doi: https://doi.org/10.1101/2020.10.15.20208041; this version posted October 19, 2020. The copyright holder for this preprint (which was not certified by peer review) is the author/funder, who has granted medRxiv a license to display the preprint in perpetuity.

All rights reserved. No reuse allowed without permission.

$1 \quad$ ILC, B cells, T:myeloid and CD4:CD8 content in airway (left) and blood (right) with outcome

2 (deceased or survived) and correlation with age. Statistical significance was calculated using

3 Mann-Whitney U-tests (box-plots) or Pearson correlations (scatter plots) and indicated by ***, p

$4 \leq 0.001 ; * *, \mathrm{p} \leq 0.01 ; *, \mathrm{p} \leq 0.05$.

Figure S4. T cell marker expression in the airways and blood of COVID-19 patients. (A) UMAP embeddings indicate site of origin for total T cells in the airway and blood of COVID-19 patients (top left) and expression of indicated T cell markers. (B) Boxplots showing mean of

8 scaled expression of $\mathrm{T}$ cell markers on total $\mathrm{T}$ cells for each patient averaged across all 9 timepoints, Statistical significance was calculated using a paired T-test and indicated by $* * *, \mathrm{p} \leq$ $0.001 ; * *, \mathrm{p} \leq 0.01 ; *, \mathrm{p} \leq 0.05$.

Figure S5. B cell subsets in airway and blood (A) UMAP embedding of the expression of key displaying expression of markers within phenograph-generated clusters for B cell subsets. The 12 phenograph clusters were collapsed into 9 subsets designated on the bottom row. Heatmaps are colored by row normalized expression values. (D) UMAP embedding of 9 B cell subsets in

17 the airway and blood. (E) Boxplots showing frequency of each B cell subset among total B cells for each patient averaged across all timepoints, Statistical significance was calculated using a paired T-test and indicated by ***, $\mathrm{p} \leq 0.001 ;{ }^{* *}, \mathrm{p} \leq 0.01{ }^{*}, \mathrm{p} \leq 0.05$.

21 Heatmap showing $\log _{2}(\mathrm{CPM}+1)$ expression of $I F N$ and $I F N$-related genes by the indicated 22 airway cell types as determined by scRNA-seq for each patient sample, indicated by color. 
medRxiv preprint doi: https://doi.org/10.1101/2020.10.15.20208041; this version posted October 19, 2020. The copyright holder for this preprint

(which was not certified by peer review) is the author/funder, who has granted medRxiv a license to display the preprint in perpetuity.

All rights reserved. No reuse allowed without permission.

2 Figure S7. Airway is the major site for production of inflammatory cytokines and

3 chemokines in COVID-19 patients. (A) Box plots showing $\log _{10}(X+1)$ normalized cytokine

4 expression profiles in the airway wash (left) and blood plasma (right) samples for an early and

5 late time point collected from 15 donors. Each dot represents an individual data point. (B)

6 Pairwise comparison of cytokine levels averaged across both timepoints in airway wash and

7 blood plasma samples collected from 15 donors. A p-value of $<0.05$ was considered significant.

8 For figures, $\mathrm{p}$-value $<0.05=*$, $\mathrm{p}$-value $<0.01=* *$ and $\mathrm{p}$-value $<0.001=* *$. 
Methods

\section{LEAD CONTACT AND MATERIALS AVAILABILITY}

3 Further information and requests for reagents should be directed to and will be fulfilled by lead

4 author Donna L. Farber (df2396@ cumc.columbia.edu)

Materials Availability Statement

This study did not generate new unique reagents.

EXPERIMENTAL MODEL AND SUBJECT DETAILS

\section{Human samples}

12 We recruited patients from and CUIMC/NYP and Morgan Stanley Children's Hospital of NY

13 with severe COVID-19 and ARDS ( $\mathrm{n}=15)$ who tested positive for SARS-CoV-2 by polymerase

14 chain reaction (PCR) from nasopharyngeal swabs (Table S1, S2). Blood and airway sampling

15 began within 24-36 hours for all patients. ARDS was defined by clinical consensus criteria;

16 including infiltrates on chest radiograph and a $\mathrm{PaO} 2 / \mathrm{FiO} 2$ ratio of less than 300 , or pediatric

17 criteria equivalent (Khemani et al., 2015; Ranieri et al., 2012). Sequential Organ Failure

18 Assessment (SOFA) scores were calculated on all hospitalized patients using previously

19 validated adult and pediatric score tools to provide additional clinical insight into patient disease

20 severity (Matics and Sanchez-Pinto, 2017; Singer et al., 2016; Vasilevskis et al., 2016). All

21 patients and samples in this study were enrolled on protocols approved by the Institutional

22 Review Board at CUIMC. Due to the limitations placed on direct contact with infected patients

23 and a need to conserve personal protective equipment, verbal informed consent was obtained 
1 from surrogates of critically ill COVID-19-ARDS patients. Healthy blood was obtained from 5

2 adult volunteers $31-57$ years.

Control, non-diseased lung tissues were obtained from deceased organ donors as part of organ acquisition for clinical transplantation through an approved protocol and material transfer agreement with LiveOnNY as described previously (Carpenter et al., 2018; Dogra et al., 2020). Donors were free of cancer, chronic diseases, seronegative for hepatitis B, C, and HIV, and negative for SARS-CoV-2 by PCR (Table S7). Use of organ donor tissues does not qualify as "human subjects" research, as confirmed by the Columbia University IRB as tissue samples were obtained from brain-dead (deceased) individuals.

\section{Processing of blood samples and isolation of PBMCs from COVID-19 patients}

12 Whole blood collected in heparinized vacutainers was centrifuged at $400 \mathrm{x} \mathrm{g}$ for $10 \mathrm{~min}$ at room 13 temperature (RT) to isolate plasma, which was then stored at $-80{ }^{\circ} \mathrm{C}$ for subsequent analysis.

14 PBMCs were isolated using Ficoll-Paque PLUS (GE) density gradient centrifugation in a Biosafety Level 2+ facility. To remove neutrophils, blood was incubated with RosetteSep

16 Granulocyte Depletion Cocktail (Stemcell Technologies), diluted 1:3 in room temperature

17 DPBS, layered over Ficoll-Paque PLUS in 50mL conical tubes, and centrifuged for 20 min at $181,200 \mathrm{x}$ g. The PBMC layer was isolated according to the manufacturer's instructions. Cells were 19 washed twice with DPBS before counting with the automated NucleoCounter NC-3000 cell 20 counter (ChemoMetec). 
medRxiv preprint doi: https://doi.org/10.1101/2020.10.15.20208041; this version posted October 19, 2020. The copyright holder for this preprint (which was not certified by peer review) is the author/funder, who has granted medRxiv a license to display the preprint in perpetuity.

All rights reserved. No reuse allowed without permission.

1 To collect airway supernatants, DPBS was added 1:1 directly to airway samples and centrifuged

2 at $400 \times \mathrm{g}$ for $10 \mathrm{~min}$ at $\mathrm{RT}$. The resulting supernatants were stored at $-80{ }^{\circ} \mathrm{C}$ for subsequent

3 analysis. To isolate airway MNCs, samples were treated with Benzonase (Millipore Sigma),

4 purified through $100 \mu \mathrm{m}$ filters, and centrifuged on a density gradient using Ficoll-Paque PLUS.

5 The MNC layer was isolated according to the manufacturer's instructions. Cells were washed

6 twice with DPBS before counting with the automated NucleoCounter NC-3000 cell counter

7 (ChemoMetec).

8

9 Cell preparation for scRNA-seq, library generation and sequencing

Airway and blood MNC populations were isolated as above, and the remaining neutrophils and

11 red blood cells were removed by incubating samples with biotinylated anti-CD66b and anti-

12 CD235ab antibodies, and depleting antibody-bound cells with streptavidin-coated magnetic

13 beads (Bangs Labs). Dead cells were subsequently removed using the Dead Cell Removal kit

14 (Miltenyi Biotec). The Next GEM Chromium Controller (10x Genomics) and Chromium Next

15 GEM Single Cell 3' Reagent kit v3.1 (10x Genomics) was used for co-encapsulation and

16 scRNA-seq library construction as per manufacturer's suggested protocols. Libraries were

17 sequenced on an Illumina NovaSeq 6000, targeting $\sim 300 \mathrm{M}$ raw reads per sample $(\sim 60,000$ raw

18 reads per cell). Sample details and number of cells sequenced in each are shown in Table S3.

20 Isolation of airway washes from non-diseased lungs

21 Non-diseased lungs were obtained from deceased organ donors as described above. Airway

22 washes were obtained by flushing out the major airway with $60 \mathrm{~mL}$ saline as described (Snyder 
medRxiv preprint doi: https://doi.org/10.1101/2020.10.15.20208041; this version posted October 19, 2020. The copyright holder for this preprint (which was not certified by peer review) is the author/funder, who has granted medRxiv a license to display the preprint in perpetuity.

1 et al., 2019). Cells were pelleted by centrifugation, resuspended in D-PBS and stained with

2 antibodies for flow cytometry.

$4 \quad$ High Dimensional Flow cytometry

5 For high parameter analysis using the Cytek Aurora panel, $5 \times 10^{6}$ cells from each site were

6 stained in $5 \mathrm{~mL}$ U-bottom tubes in the dark using the following antibody panel; Anti-Human

7 HLA-DR-BUV395, Anti-Human CD16-BUV496, Anti-Human CD163-BUV563, Anti-Human

CD33-BUV615, Anti-Human PD-1-BUV661, Anti-Human CD56-BUV737, Anti-Human CD64-

BUV805, Anti-Human CCR7-BV421, Anti-Human CD86-SB436, Anti-Human CD28-eFluor

450, Anti-Human CD8-BV480, Anti-Human CD20-Pacific Orange, Anti-Human CD3-BV510,

Anti-Human CD45RA-BV570, Anti-Human CD25-BV605, Anti-Human CD27-BV650, Anti-

Human CD69-BV711, Anti-Human CXCR5-BV750, Anti-Human CD335-BV785, Anti-Human

710, Anti-Human CD1338-PE, Anti-Human CD4-eFlour 568, Anti-Human CD123-PE-CF594,

Anti-Human CD95-PE-Cy5, Anti-Human CD11c-PE-Cy7, Anti-Human CD19-Spark NIR, Antiincubated at RT in the dark for 10 min. Following incubation, cells were washed once with cold

$21 \mu$ l human TrueStain FcX +10 ul of True-Stain Monocyte Blocker and incubated in dark for 15

22 minutes. Following incubation, cells were washed once with cold FACS-buffer and stained in a

23 two-step process. First, the cells were resuspended in a cell-surface marker staining cocktail and 
medRxiv preprint doi: https://doi.org/10.1101/2020.10.15.20208041; this version posted October 19, 2020. The copyright holder for this preprint (which was not certified by peer review) is the author/funder, who has granted medRxiv a license to display the preprint in perpetuity.

All rights reserved. No reuse allowed without permission.

1 incubated on ice for $20 \mathrm{~min}$. For intracellular staining, surface stained cells were fixed for $25 \mathrm{~min}$

2 at RT in fixing buffer (Invitrogen cat\# 00-5123-43), followed by staining in permeabilization

3 buffer (Invitrogen cat\# 00-8333-56) at RT for $30 \mathrm{~min}$. Cells were washed and data was collected

4 on 5-lazer Cytek ${ }^{\circledR}$ Aurora machine (Cytek Bio).

5

6

\section{Highly-multiplexed CodePlex chip secretome proteomics}

Cryopreserved tracheal washes and plasma were thawed at room temperature for 30-60 minutes and mixed well by pipetting up and down prior to loading. An aliquot of $5.5 \mu \mathrm{L}$ of each sample was pipetted into each macrochambers of a CodePlex chip pre-patterned with a complete copy of a 23-plex antibody array. 2\% BSA/PBS was used as background control. The chip was then loaded into an IsoLight automation system and various proteins were measured by fluorescence ELISA and analyzed by the IsoSpeak software using the IsoPlexis Human Adaptive Immune Panel: GM-CSF, Granzyme B, IFN- $\gamma$, IL-10, IL-13, IL-15, IL-17A, IL-2, IL-4, IL-5, IL-6, IL-7, IL-8, IL-9, IP-10, MCP-1, MIP-1 $\alpha$, MIP-1 $\beta$, Perforin, sCD137, TGF- $\beta 1$, TNF- $\alpha$, TNF- $\beta$.

\section{Multispectral staining and imaging of lung tissue}

Representative samples of lung tissue $0.5-1.0 \mathrm{~cm}$ in thickness were recovered from organ donors and autopsy cases of individuals diagnosed with COVID-19 and found on post-mortem exam to have pathological findings consistent with diffuse alveolar damage (Table S7). Samples were fixed in 10\% formalin (Anatech Ltd.) for 48 hours prior to dehydration and embedding in paraffin. These Lung samples were sectioned at 5-mm thickness and stained using 7-color multispectral Opal reagents (Anti-human CD19-Opal 540, Anti-human CD8-Opal 690, Antihuman CD163-Opal 650, Anti-human CD4-Opal 520, Anti-human GzmB-Opal 570, Anti-human 
medRxiv preprint doi: https://doi.org/10.1101/2020.10.15.20208041; this version posted October 19, 2020. The copyright holder for this preprint (which was not certified by peer review) is the author/funder, who has granted medRxiv a license to display the preprint in perpetuity.

All rights reserved. No reuse allowed without permission.

1 CD3-Opal 620) (Akoya Biosciences, Cat\# NEL811001KT) as previously described (Gartrell et

2 al., 2018; Weisberg et al., 2019). The multiplex panel included DAPI (BioLegend cat\# 422801)

3 for nuclear counterstaining, CD4 (1:150 dilution), CD8 (1:600 dilution), CD163 (1:200 dilution),

4 granzyme B (GzmB) (1:200 dilution), CD19 (1:50 dilution), CD3 (1:500 dilution). Single

5 controls and an unstained slide were stained with each group of slides. After staining, the

6 sections were mounted in Vectashield Hard Set mounting media (Vector Labs, Cat\#H1600) and

7 stored at $4^{0} \mathrm{C}$ for up to 48 hours prior to image acquisition. Multispectral imaging and acquisition

8 at 20x magnification (numerical aperture 0.75) was performed using the integrated Vectra

9 3automated quantitative pathology imaging system (PerkinElmer) as previously

10 described(Weisberg et al., 2019). Images were analyzed using inForm software (PerkinElmer).

11 Representative areas (10-30) from each donor were chosen for quantitative analysis.

13 Data Analysis

$14 \quad$ Flow cytometry analysis

15 Flow cytometry data was pre-gated to exclude any doublets, dead cells and CD66b ${ }^{+}$granulocytes

16 using FlowJo v 10.7 (Tree Star) (Figure S1). Cleaned data was exported as .fcs files with

17 compensated parameters and analyzed further and visualized using a Python (v3.7) (Python

18 Software Foundation. Python Language Reference, version 2.7.) computational pipeline. In brief,

19 first the data was filtered to remove any noise using quantile gates; events that fell below $0.01 \%$

20 of marker expression intensity were removed from the sample. Following initial filtering, data

21 from COVID-19 and healthy samples was merged after subsetting 70,000 events from each

22 sample. Any sample with fewer than 1000 events was removed from further analysis. The

23 merged dataset as was transformed using arcsinh function from Python numpy library(van der 
medRxiv preprint doi: https://doi.org/10.1101/2020.10.15.20208041; this version posted October 19, 2020. The copyright holder for this preprint (which was not certified by peer review) is the author/funder, who has granted medRxiv a license to display the preprint in perpetuity.

All rights reserved. No reuse allowed without permission.

1 Walt et al., 2011) after manually adjusting the cofactor for each marker. Following

2 normalization, the dataset was normalized on a 0-1 feature scale for each marker using

3 MinMaxScaler function from Python scikit-learn library (Pedregosa et al., 2011). The cleaned,

4 transformed and scaled dataset was used to run the first round of Uniform Manifold

5 Approximation and Projection (UMAP) (McInnes et al., 2018) dimensionality reduction to

6 remove any residual granulocyte contamination identified as clusters of $\mathrm{CD}^{2} 5^{\mathrm{lo}} \mathrm{CD} 66 \mathrm{~b}^{+}$cells.

7 The resulting "no neutrophil dataset" dataset was split into COVID-19 and healthy samples and

8 used for downstream analysis.

For further analysis we downsampled the "no neutrophil COVID-19 dataset" to include 20,000 events from each of 141 longitudinal samples and was used to run PCA analysis at sample level using mean expression of markers in each sample, PCA loadings provided in Table S3. We ran UMAP dimensionality reduction $(\mathrm{k}=60)$ on this dataset using 14 lineage-defining markers (CD11c, CD14, CD16, CD19, CD27, CD3, CD4, CD8, CD64, CD56, CD33, CD335, CXCR5, HLA-DR). The data were projected in 2-dimensions using UMAP embeddings and clusters of major immune cell types (CD4 and CD8 T cells, B cells, NK/ILC and Monocytes/Macrophages) were identified based on expression of lineage defining markers

17 (Figure S2B). The frequency of each lineage was averaged for individual donor-site group across all time points and used for hierarchical clustering of samples using "ward" method and 19 "jensenshannon” metric.

21 Phenograph clustering (Levine et al., 2015) on each lineage specific dataset using cell subset 22 defining markers selected based on literature review. Markers used for T cell UMAP are shown 23 in Figure S4A. B cell markers used are shown in Figure S5A and monocyte/macrophages shown 
medRxiv preprint doi: https://doi.org/10.1101/2020.10.15.20208041; this version posted October 19, 2020. The copyright holder for this preprint (which was not certified by peer review) is the author/funder, who has granted medRxiv a license to display the preprint in perpetuity.

All rights reserved. No reuse allowed without permission.

1 in Figure 3A. Major cell subset clusters were identified and functionally similar subsets were

2 coalesced and manually annotated. Heatmaps were generated for average marker expression in

3 each cluster. Data are presented as row normalized expression of marker across all clusters.

$4 \quad$ For analysis of COVID-19 and healthy samples, paired blood and airway samples across

5 all timepoints from COVID-19 donors were downsampled to 5,000 events, and each healthy

6 airway and blood sample was downsampled to 30,000 events and merged to create a reduced "no

7 neutrophil Healthy + COVID-19 dataset". UMAP dimensionality reduction and identification of

8 major cell lineages was done as described above for the COVID-19 dataset. To evaluate

9 similarity of samples by condition-site i.e. healthy-blood, healthy-airway, COVID-19-blood and

10 COVID-19-airway we calculated Minkowski distance metric (MD) (Li et al., 2011) for the

11 samples on scaled marker expression values for individual lineages using Python scipy library

12 (Jones et al., 2001). Data are presented as 1-MD (Minkowski similarity) on the heatmap; higher

13 numbers indicate increased similarity and lower numbers indicate reduced similarity between

14 samples. All graphs were generated using the Python matplotlib and seaborn libraries (Hunter, 15 2007).

\section{Classifying donor outcomes using longitudinal K-means clustering}

18 Donors were partitioned into two groups using a longitudinal K-means algorithm applied to the 19 trajectories of the frequencies of myeloid, B cell, CD4 and CD8 T cell and ILC frequencies in 20 blood and/or airways. The proximity of two donors' trajectories was defined using the sum of the

21 squared Euclidean distances between their subset frequencies at each location at each timepoint,

22 after normalizing each subset frequency across all donors and timepoints. The clustering 23 outcome was robust to this definition of distance, giving identical results when performed using 
1 log- or logit-transformed frequencies. Classification performance was defined as the percentage

2 of donors that were assigned to the correct outcome cluster (i.e. deceased or survived). We

3 compared the abilities of different immune cell subsets to distinguish donor outcome by

4 repeating the clustering analysis on different combinations of trajectories. Greater classification

5 performance indicated increased power to identify donor outcomes. Clustering analyses were

6 conducted in $R$ version 3.5.3 using the $k m l 3 d$ package, version 2.4.2, and the results were

7 visualized using the ggplot2 package.

\section{Processing of scRNA-seq Data}

We used kallisto v0.46.2 in "BUS" mode to pseudo-align the raw reads for each sample to a merged human GRCh38 (Ensembl 93)/SARS-CoV-2 transcriptome (Bray et al., 2016; Kim et al., occur on the Illumina NovaSeq 6000, we applied the algorithm of Griffiths et al (Griffiths et al., 2018) to the equivalence classes obtained from kallisto pseudo-alignment. We generated a raw count matrix from the swap-corrected BUS file using bustools v0.40.0(Melsted et al., 2019b),

16 filtered using the EmptyDrops algorithm (Lun et al., 2019), and removed all cells with

17 mitochondrial pseudo-alignment rates $>20 \%$ or counts per gene greater than two standard 18 deviations above the mean for each sample.

\section{scRNA-seq Cell Annotation}

21 We merged the scRNA-seq data from all of the airway samples and identified likely markers of

22 specific subpopulations using the previously described drop-out score method for finding genes

23 that are detected in fewer cells than expected given their expression level (Levitin et al., 2019; 
1 Szabo et al., 2019). Next, we computed a cell-by-cell Spearman's rank correlation matrix using

2 these putative marker genes. Using this matrix, we constructed a k-nearest neighbor's graph

$3(\mathrm{k}=20)$ as input for Louvain community detection as implemented in Phenograph (Levine et al.,

4 2015). To associate the resulting clusters with major cell populations in the airway, we examined

5 the statistical enrichment of the following marker genes in each cluster using the binomial test as

6 described in Shekhar et al (Shekhar et al., 2016): T cells (CD3D, TRAC, TRBC1, TRBC2, TRDC,

7 TRGC1, TRGC2), NK cells (NCAM1), myeloid cells (CD14, FCGR3A, CD163),

8 epithelial/club/goblet cells (EPCAM, SCGB1A1, MUC5B, KRT78), ionocytes (CFTR),

9 neutrophils $(C D 16 B)$, plasma cells $(C D 19, J C H A I N)$, B cells $(C D 19, M S 4 A 1)$, platelets

(ITGA2B, PF4), mast cells (KIT), dendritic cells (FCER1A, CDIC) and red blood cells (HBA1,

$11 H B A 2, H B B)$. We identified clusters as likely multiplets based on co-expression of multiple

12 marker sets (e.g. clusters enriched in both $C D 14$ and $C D 3 D$ were marked as likely $\mathrm{T}$ cell /

13 myeloid cell multiplets). All of the cells in these clusters were marked as multiplets.

In the main text, we present focused analyses on myeloid cells, $\mathrm{T}$ cells, and epithelial/club/goblet cells from the airway. To further refine our annotation, we re-clustered the cells annotated as each of these three cell types separately using the methods described above.

17 We then re-analyzed the enrichment of cell type-specific markers in the resulting new clusters.

18 As expected, this focused re-analysis of each of these three major populations identified 19 additional putative multiplet clusters and cells that we likely mis-clustered in the initial merged 20 analysis. We conducted two rounds of re-clustering for each of these three major cell types to 21 produce a refined annotation. The top of Figure S2B shows a gene expression heatmap for key 22 markers genes in the merged airway data set colored by patient and cell type annotation. We repeated the above procedure for the merged blood scRNA-seq profiles including a focused re- 
medRxiv preprint doi: https://doi.org/10.1101/2020.10.15.20208041; this version posted October 19, 2020. The copyright holder for this preprint (which was not certified by peer review) is the author/funder, who has granted medRxiv a license to display the preprint in perpetuity.

All rights reserved. No reuse allowed without permission.

1 clustering analysis of the cells that we originally annotated as myeloid and T cells for refinement.

2 The bottom of Figure S2B shows a gene expression heatmap for key markers genes in the

3 merged blood data set colored by patient and cell type annotation.

4

\section{scRNA-seq Visualization and Differential Expression Analysis}

6 We generated merged UMAP embeddings for the blood and airway $\mathrm{T}$ cells (Figure 2E, F) and

7 the blood and airway myeloid cells (Figure 4). In each case, we first identified genes that were

8 likely to contaminate either the myeloid or T cell profiles in either the blood or airway to avoid

9 including them in any of our downstream clustering, visualization, or differential expression analysis. We conducted pairwise differential expression analysis between all of the cells

11 annotated as a cell type-of-interest (e.g. myeloid) and each group of cells with a different

12 annotation for the blood and airway from each patient separately. For each pairwise comparison,

13 we randomly subsampled the two groups of cells to the same cell number. Next, we randomly

14 subsampled the molecular counts for cells in the two groups such that they have the same average number of counts per cell. We then generated a merged count matrix for the two groups and applied the pooled normalization technique from the scran package of Lun et al using the computeSumFactors function (Lun et al., 2016). Finally, we conducted a gene-by-gene, nonparametric differential expression analysis using the Mann-Whitney U-test as implemented with the function mannwhitneyu from the Python package scipy. We corrected the resulting p-values

20 for false discovery using the Benjamini-Hochberg Procedure with the function multipletests from

21 the Python package statsmodels. Using the results of pairwise differential expression analysis,

22 we generated a blacklist of genes for a given cell type by taking any gene with at least 10-fold 23 enrichment in a different cell type with FDR $<0.001$ in at least two patients. We removed all 
medRxiv preprint doi: https://doi.org/10.1101/2020.10.15.20208041; this version posted October 19, 2020. The copyright holder for this preprint (which was not certified by peer review) is the author/funder, who has granted medRxiv a license to display the preprint in perpetuity.

All rights reserved. No reuse allowed without permission.

1 genes with any enrichment in the cell type-of-interest with FDR $<0.001$ in any patient to avoid

2 eliminating patient-specific markers of the cell type-of-interest. The final blacklists for blood and

3 airway myeloid and T cells appear in Table S8.

For both myeloid and T cells, we took all of the cells in the data set that we had annotated as each of these two cell types and used the drop-out score method described above to generate a

6 list of putative, highly variable marker genes for each patient. Next, we generated a merged

7 count matrix across all patients for a given cell type, which we normalized using the pooling

8 method of Lun et al as described above (Lun et al., 2016). We then generated a log-normalized

9 submatrix $\left(\log _{2}(\right.$ counts per million +1$\left.)\right)$ containing the union of the marker gene sets identified

for each patient after removing genes on the airway and blood blacklists for the cell type-of-

11 interest. Using the PCA function in the Python package scikit-learn, we decomposed this

12 submatrix into its principal components. We used the 10 principal components with the largest

13 eigenvalues as input to the scRNA-seq batch correction algorithm Harmony (Korsunsky et al.,

14 2019). We made the function HarmonyMatrix aware of only the first 10 principal components

15 and the patient identifiers for each cell. Finally, we computed a two-dimensional embedding

16 using the Python implementation of the Uniform Manifold Approximation and Projection

17 (UMAP) algorithm (McInnes and Healy, 2018) and the Pearson correlation matrix of the

18 Harmony-corrected principal components. These embeddings appear in Figures 2 and 4.

For the differential expression analysis between blood and airway myeloid cells and

20 between blood and airway T cells, we used the Mann-Whitney U-test approach described above.

21 We removed genes on the blacklists described above for each cell type prior to subsampling,

22 normalization, and statistical testing. We also restricted this analysis to protein-coding genes and

23 removed all $\mathrm{T}$ cell receptor and immunoglobulin variable regions. We performed differential 
1 expression separately on each pair of matched airway and blood samples (there are 12 patient

2 time points for which we have matched samples). Stringent criteria were used to select the

3 differentially expressed genes displayed in the heatmaps in Figures 2 and 4. For the myeloid cell

4 heatmap in Figure 4, a gene had to be differentially expressed with a fold-change of at least 4 in

5 either direction and FDR $<0.001$ in at least 9 of the 12 matched sample pairs. For the $\mathrm{T}$ cell

6 heatmap in Figure 2, we applied the first two criteria, but required them in only 6 of the 12

7 matched sample pairs. Results for all of the pairwise differential expression analyses comparing

8 airway and blood T and myeloid cells can be found in Table S5 and Table S6, respectively.

\section{Analysis and visualization of Cytokine data}

11 Cytokine expression data from early and late time points was $\log _{10}$ normalized and visualized as

12 box plots overlaid with individual data points. The $\log _{10}$ normalized data was averaged across

13 both the time points and used to generate heatmaps for cytokine expression across individual

14 donor samples. Non-log transformed cytokine expression data from both time points was

15 averaged for airway and plasma from each donor and used for paired-site analysis. Graphs were

16 generated using the Python matplotlib and seaborn libraries (Hunter, 2007). All code for analysis

17 of data and generation of figures will be hosted on GitHub.

\section{Lung tissue imaging analysis}

20 Tissue segmentation was performed using inForm software on 10-30 representative fields

21 (Version 2.3, PerkinElmer). Immune cell constituents within each tissue segment were defined

22 by the DAPI nuclear counterstain to define the nucleus of each cell, with each associated

23 membrane detected via presence of a specific stain (CD3, CD19, CD4, GzmB and/or CD163). 
1 Cell segmentation was adjusted as previously described to accurately locate all cells and

2 minimize nuclear hypersegmentation and hyposegmentation (Weisberg et al., 2019). Cells were

3 then phenotyped by training the phenotyping algorithm of inForm software, identifying:

4 macrophage (CD163+ magenta cells), $\mathrm{T}$ cells (CD4 ${ }^{+}$cyan cells and $\mathrm{CD}^{+}$orange cells), $\mathrm{B}$ cells

5 (CD19 $^{+}$yellow cells). The cell segmentation data summary provided densities and numbers of

6 each cell type in the lung tissue segments and the full cell segmentation data file provided the $\mathrm{X}$

7 and Y coordinates of each phenotyped cell.

$9 \quad$ Statistical Analysis

10 Differences in mean between two sample groups were compared using Mann-Whitney U test, 11 multiple group comparisons were done using ANOVA followed by Tukey's HSD post-test and 12 paired t-test for any paired data custom scripts based on Python sciPy library (Jones et al., 2001). $13 \quad P$-values below 0.05 were considered as statistically significant. For all figures $* * *=\mathrm{p}$-value $<$ $0.001, * *=\mathrm{p}$-value $<0.01$, and $*=\mathrm{p}$-value $<0.05$

\section{DATA AND CODE AVAILABILITY}

17 The scRNA-seq data for each sample including count matrices, normalized counts, metadata, cell annotations, and UMAP embeddings are available on the COVID-19 Cell Atlas along with interactive visualizations (https://www.covid19cellatlas.org/index.patient.html). The scRNA-seq data analysis code is available at www.github.com/simslab/cluster_diffex2018. 
medRxiv preprint doi: https://doi.org/10.1101/2020.10.15.20208041; this version posted October 19, 2020. The copyright holder for this preprint

(which was not certified by peer review) is the author/funder, who has granted medRxiv a license to display the preprint in perpetuity.

All rights reserved. No reuse allowed without permission.

\section{Supplementary Tables}

2 Table S1. Clinical information for COVID-19 patients in this study.

3 Table S2. Assays performed on the samples from individual COVID-19 patients.

4 Table S3. Summary of sample details for scRNA-seq analysis.

5 Table S4. PCA loadings of markers for PC1 and PC2.

6 Table S5. Differential gene expression by T cells in airway versus blood for each sample by

7 scRNA-seq.

8 Table S6. Differential gene expression by myeloid cells in airway versus blood for each sample

9 by scRNA-seq.

10 Table S7. Deceased donors for control airway and COVID-19 lung autopsy samples

11 Table S8. Blacklisted genes for a given cell type for the scRNAseq analysis. 


\section{REFERENCES}

Aggarwal, N.R., King, L.S., and D'Alessio, F.R. (2014). Diverse macrophage populations mediate acute lung inflammation and resolution. Am J Physiol Lung Cell Mol Physiol 306, L709-725.

Allen, A.C., Wilk, M.M., Misiak, A., Borkner, L., Murphy, D., and Mills, K.H.G. (2018). Sustained protective immunity against Bordetella pertussis nasal colonization by intranasal immunization with a vaccine-adjuvant combination that induces IL-17-secreting TRM cells. Mucosal Immunol 11, 1763-1776.

Bharat, A., Bhorade, S.M., Morales-Nebreda, L., McQuattie-Pimentel, A.C., Soberanes, S., Ridge, K., DeCamp, M.M., Mestan, K.K., Perlman, H., Budinger, G.R., and Misharin, A.V. (2016). Flow Cytometry Reveals Similarities Between Lung Macrophages in Humans and Mice. Am J Respir Cell Mol Biol 54, 147-149.

Bray, N.L., Pimentel, H., Melsted, P., and Pachter, L. (2016). Near-optimal probabilistic RNAseq quantification. Nature biotechnology 34, 525-527.

Buechler, C., Ritter, M., Orso, E., Langmann, T., Klucken, J., and Schmitz, G. (2000). Regulation of scavenger receptor CD163 expression in human monocytes and macrophages by pro- and antiinflammatory stimuli. J Leukoc Biol 67, 97-103.

Carpenter, D.J., Granot, T., Matsuoka, N., Senda, T., Kumar, B.V., Thome, J.J.C., Gordon, C.L., Miron, M., Weiner, J., Connors, T., Lerner, H., Friedman, A., Kato, T., Griesemer, A.D., and Farber, D.L. (2018). Human immunology studies using organ donors: Impact of clinical variations on immune parameters in tissues and circulation. Am J Transplant 18, 74-88.

Chau, A.S., Weber, A.G., Maria, N.I., Narain, S., Liu, A., Hajizadeh, N., Malhotra, P., Bloom, O., Marder, G., and Kaplan, B. (2020). The Longitudinal Immune Response to Coronavirus Disease 2019: Chasing the Cytokine Storm. Arthritis Rheumatol.

Choi, Y.S., Gullicksrud, J.A., Xing, S., Zeng, Z., Shan, Q., Li, F., Love, P.E., Peng, W., Xue, H.H., and Crotty, S. (2015). LEF-1 and TCF-1 orchestrate T(FH) differentiation by regulating differentiation circuits upstream of the transcriptional repressor Bcl6. Nat Immunol 16, 980-990.

Connors, T.J., Baird, J.S., Yopes, M.C., Zens, K.D., Pethe, K., Ravindranath, T.M., Ho, S.H., and Farber, D.L. (2018). Developmental Regulation of Effector and Resident Memory T Cell Generation during Pediatric Viral Respiratory Tract Infection. J Immunol 201, 432-439. 
Connors, T.J., Ravindranath, T.M., Bickham, K.L., Gordon, C.L., Zhang, F., Levin, B., Baird, J.S., and Farber, D.L. (2016). Airway CD8(+) T Cells Are Associated with Lung Injury during Infant Viral Respiratory Tract Infection. Am J Respir Cell Mol Biol 54, 822-830.

Copaescu, A., Smibert, O., Gibson, A., Phillips, E.J., and Trubiano, J.A. (2020). The role of IL-6 and other mediators in the cytokine storm associated with SARS-CoV-2 infection. J Allergy Clin Immunol 146, 518-534 e511.

Cummings, M.J., Baldwin, M.R., Abrams, D., Jacobson, S.D., Meyer, B.J., Balough, E.M., Aaron, J.G., Claassen, J., Rabbani, L.E., Hastie, J., Hochman, B.R., Salazar-Schicchi, J., Yip, N.H., Brodie, D., and O'Donnell, M.R. (2020). Epidemiology, clinical course, and outcomes of critically ill adults with COVID-19 in New York City: a prospective cohort study. Lancet 395, 1763-1770.

Damiani, S., Fiorentino, M., De Palma, A., Foschini, M.P., Lazzarotto, T., Gabrielli, L., Viale, P.L., Attard, L., Riefolo, M., and D'Errico, A. (2020). Pathological Post Mortem Findings in Lungs Infected With Sars-Cov 2. J Pathol.

Darrah, P.A., Zeppa, J.J., Maiello, P., Hackney, J.A., Wadsworth, M.H., 2nd, Hughes, T.K., Pokkali, S., Swanson, P.A., 2nd, Grant, N.L., Rodgers, M.A., et al. (2020). Prevention of tuberculosis in macaques after intravenous BCG immunization. Nature 577, 95-102.

Davies, N.G., Klepac, P., Liu, Y., Prem, K., Jit, M., group, C.C.-w., and Eggo, R.M. (2020). Age-dependent effects in the transmission and control of COVID-19 epidemics. Nat Med 26, 1205-1211.

De Michele, S., Sun, Y., Yilmaz, M.M., Katsyv, I., Salvatore, M., Dzierba, A.L., Marboe, C.C., Brodie, D., Patel, N.M., Garcia, C.K., and Saqi, A. (2020). Forty Postmortem Examinations in COVID-19 Patients. Am J Clin Pathol.

Della-Torre, E., Campochiaro, C., Cavalli, G., De Luca, G., Napolitano, A., La Marca, S., Boffini, N., Da Prat, V., Di Terlizzi, G., Lanzillotta, M., et al. (2020). Interleukin-6 blockade with sarilumab in severe COVID-19 pneumonia with systemic hyperinflammation: an open-label cohort study. Ann Rheum Dis 79, 1277-1285.

Dogra, P., Rancan, C., Ma, W., Toth, M., Senda, T., Carpenter, D.J., Kubota, M., Matsumoto, R., Thapa, P., Szabo, P.A., Li Poon, M.M., Li, J., Arakawa-Hoyt, J., Shen, Y., Fong, L., Lanier, L.L., and Farber, D.L. (2020). Tissue Determinants of Human NK Cell Development, Function, and Residence. Cell 180, 749-763 e713. 
Farhadian, S., Glick, L.R., Vogels, C.B.F., Thomas, J., Chiarella, J., Casanovas-Massana, A., Zhou, J., Odio, C., Vijayakumar, P., Geng, B., et al. (2020). Acute encephalopathy with elevated CSF inflammatory markers as the initial presentation of COVID-19. BMC Neurol 20, 248.

Furlow, B. (2020). COVACTA trial raises questions about tocilizumab's benefit in COVID-19. Lancet Rheumatol.

Gartrell, R.D., Marks, D.K., Hart, T.D., Li, G., Davari, D.R., Wu, A., Blake, Z., Lu, Y., Askin, K.N., Monod, A., et al. (2018). Quantitative Analysis of Immune Infiltrates in Primary Melanoma. Cancer Immunol Res 6, 481-493.

Griffiths, J.A., Richard, A.C., Bach, K., Lun, A.T.L., and Marioni, J.C. (2018). Detection and removal of barcode swapping in single-cell RNA-seq data. Nature communications 9, 2667.

Grifoni, A., Weiskopf, D., Ramirez, S.I., Mateus, J., Dan, J.M., Moderbacher, C.R., Rawlings, S.A., Sutherland, A., Premkumar, L., Jadi, R.S., et al. (2020). Targets of T Cell Responses to SARS-CoV-2 Coronavirus in Humans with COVID-19 Disease and Unexposed Individuals. Cell $181,1489-1501$ e1415.

Hadjadj, J., Yatim, N., Barnabei, L., Corneau, A., Boussier, J., Smith, N., Pere, H., Charbit, B., Bondet, V., Chenevier-Gobeaux, C., et al. (2020). Impaired type I interferon activity and inflammatory responses in severe COVID-19 patients. Science 369, 718-724.

Hassan, A.O., Kafai, N.M., Dmitriev, I.P., Fox, J.M., Smith, B.K., Harvey, I.B., Chen, R.E., Winkler, E.S., Wessel, A.W., Case, J.B., et al. (2020). A Single-Dose Intranasal ChAd Vaccine Protects Upper and Lower Respiratory Tracts against SARS-CoV-2. Cell 183, 169-184 e113.

Hendrix, A.Y., and Kheradmand, F. (2017). The Role of Matrix Metalloproteinases in Development, Repair, and Destruction of the Lungs. Prog Mol Biol Transl Sci 148, 1-29.

Hunter, J.D. (2007). Matplotlib: A 2D graphics environment. Computing In Science and Engineering 9, 90-95.

Jeyanathan, M., Afkhami, S., Smaill, F., Miller, M.S., Lichty, B.D., and Xing, Z. (2020). Immunological considerations for COVID-19 vaccine strategies. Nat Rev Immunol.

Jones, E., Oliphant, T., and Peterson, P. (2001). SciPy: Open source scientific tools for Python. 
Kapellos, T.S., Bonaguro, L., Gemund, I., Reusch, N., Saglam, A., Hinkley, E.R., and Schultze, J.L. (2019). Human Monocyte Subsets and Phenotypes in Major Chronic Inflammatory Diseases. Front Immunol 10, 2035.

Khemani, R.G., Smith, L.S., Zimmerman, J.J., Erickson, S., and Pediatric Acute Lung Injury Consensus Conference, G. (2015). Pediatric acute respiratory distress syndrome: definition, incidence, and epidemiology: proceedings from the Pediatric Acute Lung Injury Consensus Conference. Pediatr Crit Care Med 16, S23-40.

Kim, D., Lee, J.Y., Yang, J.S., Kim, J.W., Kim, V.N., and Chang, H. (2020). The Architecture of SARS-CoV-2 Transcriptome. Cell 181, 914-921 e910.

Korsunsky, I., Millard, N., Fan, J., Slowikowski, K., Zhang, F., Wei, K., Baglaenko, Y., Brenner, M., Loh, P.-r., and Raychaudhuri, S. (2019). Fast, sensitive and accurate integration of singlecell data with Harmony. Nature methods, 1-8.

Kumar, B.V., Connors, T.J., and Farber, D.L. (2018). Human T Cell Development, Localization, and Function throughout Life. Immunity 48, 202-213.

Kumar, B.V., Ma, W., Miron, M., Granot, T., Guyer, R.S., Carpenter, D.J., Senda, T., Sun, X., Ho, S.H., Lerner, H., Friedman, A.L., Shen, Y., and Farber, D.L. (2017). Human Tissue-Resident Memory T Cells Are Defined by Core Transcriptional and Functional Signatures in Lymphoid and Mucosal Sites. Cell Rep 20, 2921-2934.

Kuri-Cervantes, L., Pampena, M.B., Meng, W., Rosenfeld, A.M., Ittner, C.A.G., Weisman, A.R., Agyekum, R.S., Mathew, D., Baxter, A.E., Vella, L.A., et al. (2020). Comprehensive mapping of immune perturbations associated with severe COVID-19. Sci Immunol 5.

Laing, A.G., Lorenc, A., Del Molino Del Barrio, I., Das, A., Fish, M., Monin, L., Munoz-Ruiz, M., McKenzie, D.R., Hayday, T.S., Francos-Quijorna, I., et al. (2020). A dynamic COVID-19 immune signature includes associations with poor prognosis. Nat Med.

Levine, J.H., Simonds, E.F., Bendall, S.C., Davis, K.L., Amir el, A.D., Tadmor, M.D., Litvin, O., Fienberg, H.G., Jager, A., Zunder, E.R., Finck, R., Gedman, A.L., Radtke, I., Downing, J.R., Pe'er, D., and Nolan, G.P. (2015). Data-Driven Phenotypic Dissection of AML Reveals Progenitor-like Cells that Correlate with Prognosis. Cell 162, 184-197.

Levitin, H.M., Yuan, J., Cheng, Y.L., Ruiz, F.J.R., Bush, E.C., Bruce, J.N., Canoll, P., Iavarone, A., Lasorella, A., Blei, D.M., and Sims, P.A. (2019). De novo Gene Signature Identification 
from Single-Cell RNA-seq with Hierarchical Poisson Factorization. Molecular Systems Biology 15 .

Li, Z., Ding, Q., and Zhang, W. (2011). A Comparative Study of Different Distances for Similarity Estimation. . In Intelligent Computing and Information Science ICICIS 2011 Communications in Computer and Information Science, R. Chen, ed. (Berlin: Springer).

Liao, M., Liu, Y., Yuan, J., Wen, Y., Xu, G., Zhao, J., Cheng, L., Li, J., Wang, X., Wang, F., Liu, L., Amit, I., Zhang, S., and Zhang, Z. (2020). Single-cell landscape of bronchoalveolar immune cells in patients with COVID-19. Nat Med 26, 842-844.

Lin, K.L., Suzuki, Y., Nakano, H., Ramsburg, E., and Gunn, M.D. (2008). CCR2+ monocytederived dendritic cells and exudate macrophages produce influenza-induced pulmonary immune pathology and mortality. J Immunol 180, 2562-2572.

Lin, K.L., Sweeney, S., Kang, B.D., Ramsburg, E., and Gunn, M.D. (2011). CCR2-antagonist prophylaxis reduces pulmonary immune pathology and markedly improves survival during influenza infection. J Immunol 186, 508-515.

Long, Q.X., Liu, B.Z., Deng, H.J., Wu, G.C., Deng, K., Chen, Y.K., Liao, P., Qiu, J.F., Lin, Y., Cai, X.F., et al. (2020). Antibody responses to SARS-CoV-2 in patients with COVID-19. Nat Med 26, 845-848.

Lucas, C., Wong, P., Klein, J., Castro, T.B.R., Silva, J., Sundaram, M., Ellingson, M.K., Mao, T., Oh, J.E., Israelow, B., et al. (2020). Longitudinal analyses reveal immunological misfiring in severe COVID-19. Nature 584, 463-469.

Lun, A.T., Bach, K., and Marioni, J.C. (2016). Pooling across cells to normalize single-cell RNA sequencing data with many zero counts. Genome biology 17,75 .

Lun, A.T., Riesenfeld, S., Andrews, T., Gomes, T., and Marioni, J.C. (2019). EmptyDrops: distinguishing cells from empty droplets in droplet-based single-cell RNA sequencing data. Genome biology 20, 1-9.

Mackay, L.K., Minnich, M., Kragten, N.A., Liao, Y., Nota, B., Seillet, C., Zaid, A., Man, K., Preston, S., Freestone, D., et al. (2016). Hobit and Blimp1 instruct a universal transcriptional program of tissue residency in lymphocytes. Science 352, 459-463. 
Masopust, D., and Soerens, A.G. (2019). Tissue-Resident T Cells and Other Resident Leukocytes. Annu Rev Immunol 37, 521-546.

Mathew, D., Giles, J.R., Baxter, A.E., Oldridge, D.A., Greenplate, A.R., Wu, J.E., Alanio, C., Kuri-Cervantes, L., Pampena, M.B., D'Andrea, K., et al. (2020). Deep immune profiling of COVID-19 patients reveals distinct immunotypes with therapeutic implications. Science 369.

Matics, T.J., and Sanchez-Pinto, L.N. (2017). Adaptation and Validation of a Pediatric Sequential Organ Failure Assessment Score and Evaluation of the Sepsis-3 Definitions in Critically Ill Children. JAMA Pediatr 171, e172352.

McInnes, L., and Healy, J. (2018). UMAP: Uniform Manifold Approximation and Projection for Dimension Reduction. arXiv, arXiv:1802.03426.

McInnes, L., Healy, J., Saul, N., and Grossberger, L. (2018). UMAP: Uniform Manifold Approximation and Projection. J Open Source Software 3, 861.

Melsted, P., Booeshaghi, A.S., Gao, F., Beltrame, E., Lu, L., Hjorleifsson, K.E., Gehring, J., and Pachter, L. (2019a). Modular and efficient pre-processing of single-cell RNA-seq. bioRxiv, 673285 .

Melsted, P., Ntranos, V., and Pachter, L. (2019b). The barcode, UMI, set format and BUStools. Bioinformatics (Oxford, England) 35, 4472-4473.

Moderbacher, C.R., Ramirez, S.I., Dan, J.M., Grifoni, A., Hastie, K.M., Weiskopf, D., Belanger, S., Abbott, R.K., Kim, C., Choi, J., et al. (2020). Antigen-specific adaptive immunity to SARSCoV-2 in acute COVID-19 and

associations with age and disease severity. Cell https://doi.org/10.1016/j.cell.2020.09.038.

Morrell, E.D., Bhatraju, P.K., Mikacenic, C.R., Radella, F., 2nd, Manicone, A.M., Stapleton, R.D., Wurfel, M.M., and Gharib, S.A. (2019). Alveolar Macrophage Transcriptional Programs Are Associated with Outcomes in Acute Respiratory Distress Syndrome. Am J Respir Crit Care Med 200, 732-741.

Ni, L., Ye, F., Cheng, M.L., Feng, Y., Deng, Y.Q., Zhao, H., Wei, P., Ge, J., Gou, M., Li, X., et al. (2020). Detection of SARS-CoV-2-Specific Humoral and Cellular Immunity in COVID-19 Convalescent Individuals. Immunity 52, 971-977 e973. 
Paik, D., and Farber, D.L. (2020). Influenza infection fortifies local lymph nodes to promote lung resident heterosubtypic immunity. J Exp Med in Revision.

Pedregosa, F., Varoquaux, G., Gramfort, A., Michel, V., Thirion, B., Grisel, O., Blondel, M., Prettenhofer, P., Weiss, R., Dubourg, V., Vanderplas, J., Passos, A., Cournapeau, D., Brucher, M., Perrot, M., and Duchesnay, E. (2011). Scikit-learn: Machine Learning in Python. J Mach Learn Res 12, 2825-2830.

Ranieri, V.M., Rubenfeld, G.D., Thompson, B.T., Ferguson, N.D., Caldwell, E., Fan, E., Camporota, L., and Slutsky, A.S. (2012). Acute respiratory distress syndrome: the Berlin Definition. JAMA 307, 2526-2533.

Schulte-Schrepping, J., Reusch, N., Paclik, D., Bassler, K., Schlickeiser, S., Zhang, B., Kramer, B., Krammer, T., Brumhard, S., Bonaguro, L., et al. (2020). Severe COVID-19 Is Marked by a Dysregulated Myeloid Cell Compartment. Cell 182, 1419-1440 e1423.

Schultze, J.L., Mass, E., and Schlitzer, A. (2019). Emerging Principles in Myelopoiesis at Homeostasis and during Infection and Inflammation. Immunity 50, 288-301.

Shekhar, K., Lapan, S.W., Whitney, I.E., Tran, N.M., Macosko, E.Z., Kowalczyk, M., Adiconis, X., Levin, J.Z., Nemesh, J., Goldman, M., McCarroll, S.A., Cepko, C.L., Regev, A., and Sanes, J.R. (2016). Comprehensive Classification of Retinal Bipolar Neurons by Single-Cell Transcriptomics. Cell 166, 1308-1323 e1330.

Shi, C., Jia, T., Mendez-Ferrer, S., Hohl, T.M., Serbina, N.V., Lipuma, L., Leiner, I., Li, M.O., Frenette, P.S., and Pamer, E.G. (2011). Bone marrow mesenchymal stem and progenitor cells induce monocyte emigration in response to circulating toll-like receptor ligands. Immunity 34, 590-601.

Silvin, A., Chapuis, N., Dunsmore, G., Goubet, A.G., Dubuisson, A., Derosa, L., Almire, C., Henon, C., Kosmider, O., Droin, N., et al. (2020). Elevated Calprotectin and Abnormal Myeloid Cell Subsets Discriminate Severe from Mild COVID-19. Cell 182, 1401-1418 e1418.

Singer, M., Deutschman, C.S., Seymour, C.W., Shankar-Hari, M., Annane, D., Bauer, M., Bellomo, R., Bernard, G.R., Chiche, J.D., Coopersmith, C.M., Hotchkiss, R.S., Levy, M.M., Marshall, J.C., Martin, G.S., Opal, S.M., Rubenfeld, G.D., van der Poll, T., Vincent, J.L., and Angus, D.C. (2016). The Third International Consensus Definitions for Sepsis and Septic Shock (Sepsis-3). JAMA 315, 801-810. 
Snyder, M.E., Finlayson, M.O., Connors, T.J., Dogra, P., Senda, T., Bush, E., Carpenter, D., Marboe, C., Benvenuto, L., Shah, L., et al. (2019). Generation and persistence of human tissueresident memory $\mathrm{T}$ cells in lung transplantation. Sci Immunol 4, eaav5581.

Szabo, P.A., Levitin, H.M., Miron, M., Snyder, M.E., Senda, T., Yuan, J., Cheng, Y.L., Bush, E.C., Dogra, P., Thapa, P., Farber, D.L., and Sims, P.A. (2019). Single-cell transcriptomics of human $\mathrm{T}$ cells reveals tissue and activation signatures in health and disease. Nat Commun 10, 4706.

Takahashi, T., Ellingson, M.K., Wong, P., Israelow, B., Lucas, C., Klein, J., Silva, J., Mao, T., Oh, J.E., Tokuyama, M., et al. (2020). Sex differences in immune responses that underlie COVID-19 disease outcomes. Nature.

Teijaro, J.R., Turner, D., Pham, Q., Wherry, E.J., Lefrancois, L., and Farber, D.L. (2011a). Cutting edge: tissue-retentive lung memory CD4 $\mathrm{T}$ cells mediate optimal protection to respiratory virus infection. J Immunol 187, 5510-5514.

Teijaro, J.R., Walsh, K.B., Cahalan, S., Fremgen, D.M., Roberts, E., Scott, F., Martinborough, E., Peach, R., Oldstone, M.B., and Rosen, H. (2011b). Endothelial cells are central orchestrators of cytokine amplification during influenza virus infection. Cell 146, 980-991.

Thieme, C.J., Anft, M., Paniskaki, K., Blazquez-Navarro, A., Doevelaar, A., Seibert, F.S., Hoelzer, B., Konik, M.J., Brenner, T., Tempfer, C., et al. (2020). Robust T cell response towards spike, membrane, and nucleocapsid SARS-CoV-2 proteins is not associated with recovery in critical COVID-19 patients. Cell Rep Med, 100092.

Turner, D.L., Bickham, K.L., Thome, J.J., Kim, C.Y., D'Ovidio, F., Wherry, E.J., and Farber, D.L. (2014). Lung niches for the generation and maintenance of tissue-resident memory T cells. Mucosal Immunol 7, 501-510.

Turner, D.L., and Farber, D.L. (2014). Mucosal resident memory CD4 T cells in protection and immunopathology. Front Immunol 5, 331.

van der Walt, S., Colbert, S.C., and Varoquaux, G. (2011). The NumPy Array: A Structure for Efficient Numerical Computation. Computing in Science \& Engineering 13, 22-30.

Vasilevskis, E.E., Pandharipande, P.P., Graves, A.J., Shintani, A., Tsuruta, R., Ely, E.W., and Girard, T.D. (2016). Validity of a Modified Sequential Organ Failure Assessment Score Using the Richmond Agitation-Sedation Scale. Crit Care Med 44, 138-146. 
Venet, F., Demaret, J., Gossez, M., and Monneret, G. (2020). Myeloid cells in sepsis-acquired immunodeficiency. Ann N Y Acad Sci.

Veras, F.P., Pontelli, M.C., Silva, C.M., Toller-Kawahisa, J.E., de Lima, M., Nascimento, D.C., Schneider, A.H., Caetite, D., Tavares, L.A., Paiva, I.M., et al. (2020). SARS-CoV-2-triggered neutrophil extracellular traps mediate COVID-19 pathology. J Exp Med 217.

Weisberg, S.P., Carpenter, D.J., Chait, M., Dogra, P., Gartrell-Corrado, R.D., Chen, A.X., Campbell, S., Liu, W., Saraf, P., Snyder, M.E., Kubota, M., Danzl, N.M., Schrope, B.A., Rabadan, R., Saenger, Y., Chen, X., and Farber, D.L. (2019). Tissue-Resident Memory T Cells Mediate Immune Homeostasis in the Human Pancreas through the PD-1/PD-L1 Pathway. Cell Rep 29, 3916-3932 e3915.

Weisberg, S.P., Connors, T., Zhu, Y., Baldwin, M., Lin, W.H., Wontakal, S., Szabo, P.A., Wells, S.B., Dogra, P., Gray, J.I., et al. (2020). Antibody responses to SARS-CoV2 are distinct in children with MIS-C compared to adults with COVID-19. medRxiv.

Weisel, N.M., Weisel, F.J., Farber, D.L., Borghesi, L.A., Shen, Y., Ma, W., Luning Prak, N.T., and Shlomchik, M.J. (2020). Comprehensive analysis of B cell compartments across the human body reveals novel subsets and a gut resident memory phenotype. Blood In Press.

Weiskopf, D., Schmitz, K.S., Raadsen, M.P., Grifoni, A., Okba, N.M.A., Endeman, H., van den Akker, J.P.C., Molenkamp, R., Koopmans, M.P.G., van Gorp, E.C.M., Haagmans, B.L., de Swart, R.L., Sette, A., and de Vries, R.D. (2020). Phenotype and kinetics of SARS-CoV-2specific T cells in COVID-19 patients with acute respiratory distress syndrome. Sci Immunol 5.

Wu, T., Hu, Y., Lee, Y.T., Bouchard, K.R., Benechet, A., Khanna, K., and Cauley, L.S. (2014). Lung-resident memory CD8 T cells (TRM) are indispensable for optimal cross-protection against pulmonary virus infection. J Leukoc Biol 95, 215-224.

Wu, Z., and McGoogan, J.M. (2020). Characteristics of and Important Lessons From the Coronavirus Disease 2019 (COVID-19) Outbreak in China: Summary of a Report of 72314 Cases From the Chinese Center for Disease Control and Prevention. JAMA.

Yoo, J.K., Kim, T.S., Hufford, M.M., and Braciale, T.J. (2013). Viral infection of the lung: host response and sequelae. J Allergy Clin Immunol 132, 1263-1276. 
medRxiv preprint doi: https://doi.org/10.1101/2020.10.15.20208041; this version posted October 19, 2020. The copyright holder for this preprint (which was not certified by peer review) is the author/funder, who has granted medRxiv a license to display the preprint in perpetuity. All rights reserved. No reuse allowed without permission.

1 Zens, K.D., Chen, J.-K., and Farber, D.L. (2016). Vaccine-Generated Lung Tissue-Resident 2 Memory T cells Provide Heterosubtypic Protection to Influenza Infection. J Clin Invest Insight 1 $3 \mathrm{e} 85832$.

4

5 Zhao, J., Zhao, J., Mangalam, A.K., Channappanavar, R., Fett, C., Meyerholz, D.K., 6 Agnihothram, S., Baric, R.S., David, C.S., and Perlman, S. (2016). Airway Memory CD4(+) T 7 Cells Mediate Protective Immunity against Emerging Respiratory Coronaviruses. Immunity 44, $8 \quad 1379-1391$. 
medRxiv preprint doi: https://doi.org/10.1101/2020.10.15.20208041; this version posted October 19, 2020. The copyright holder for this preprint Figure 2.

A

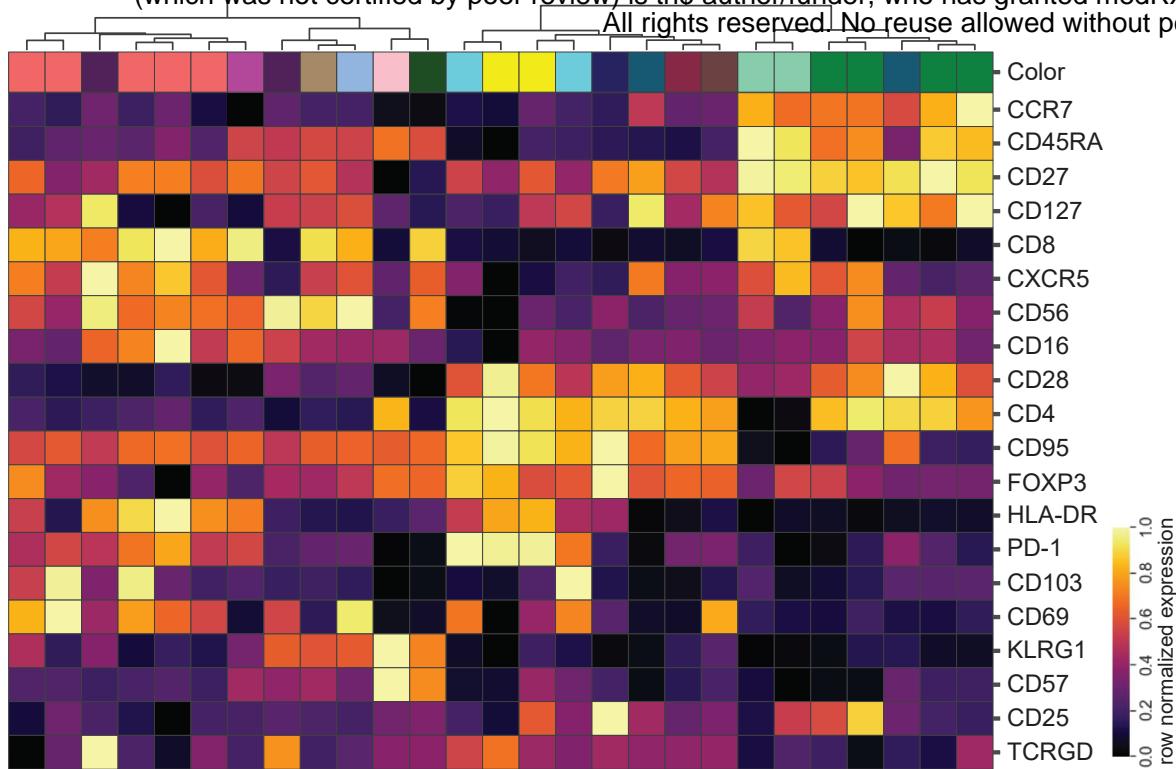

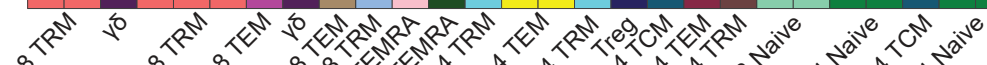

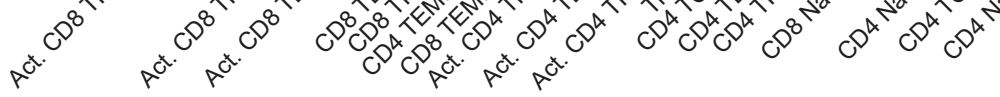

C
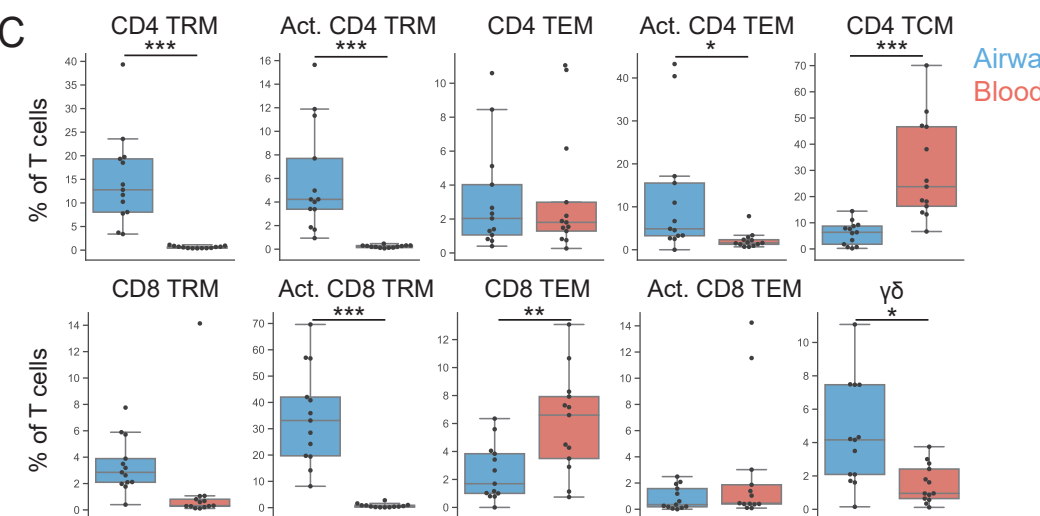

Act. CD8 TRM
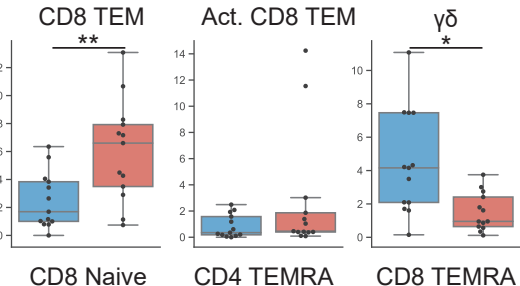

CD4 TEMRA

CD8 TEMRA

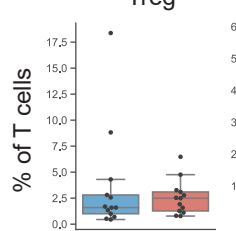

CD4 Naive

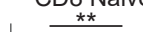

E
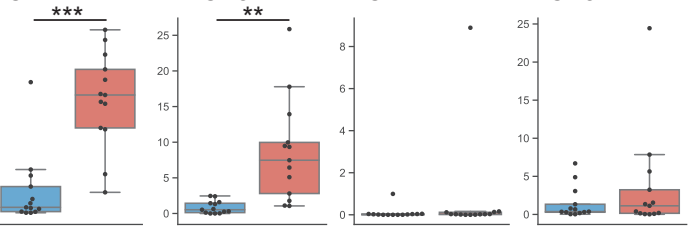

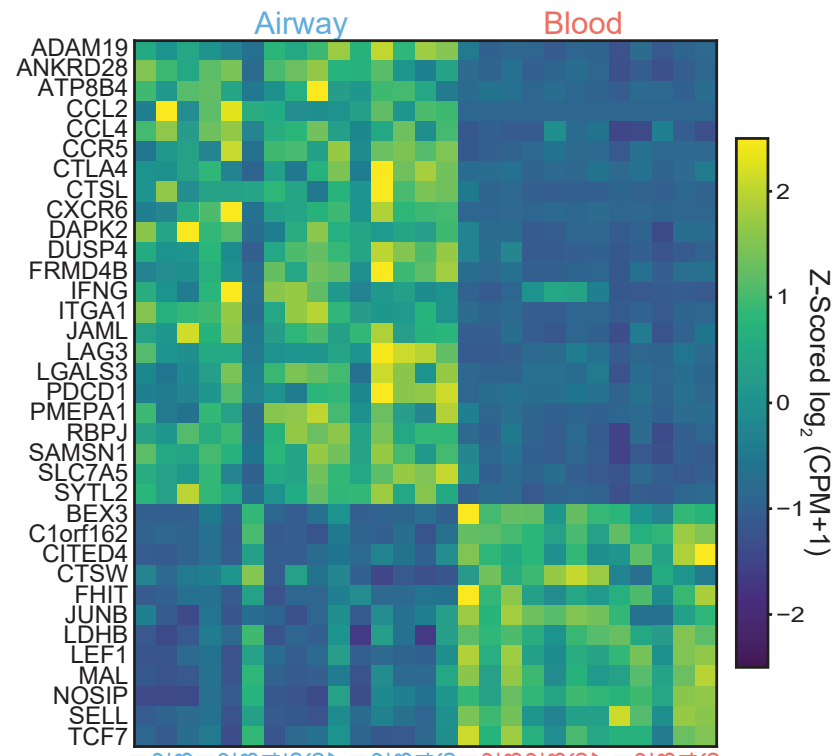

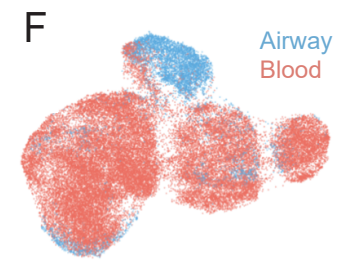

CD8
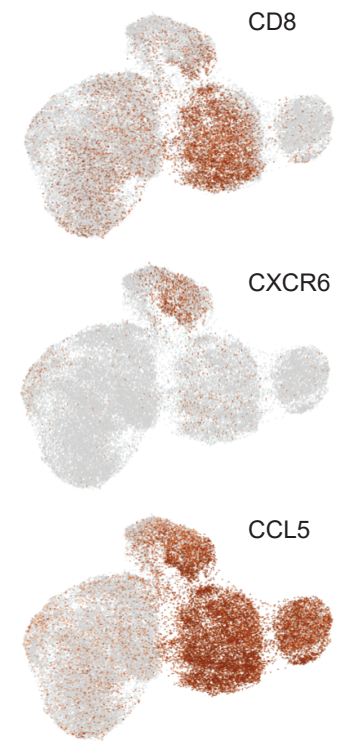
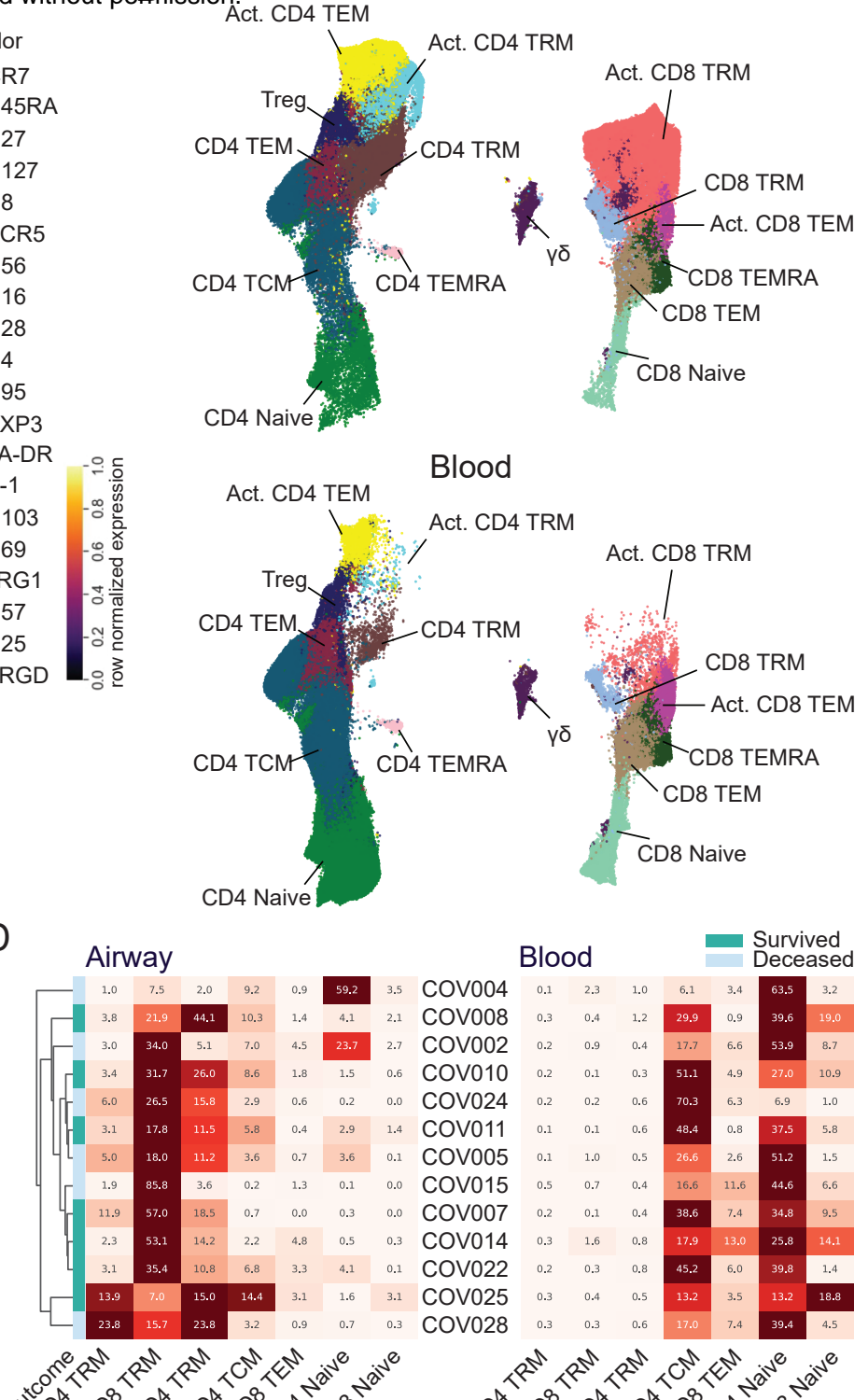

0,000 be.

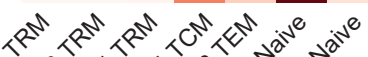
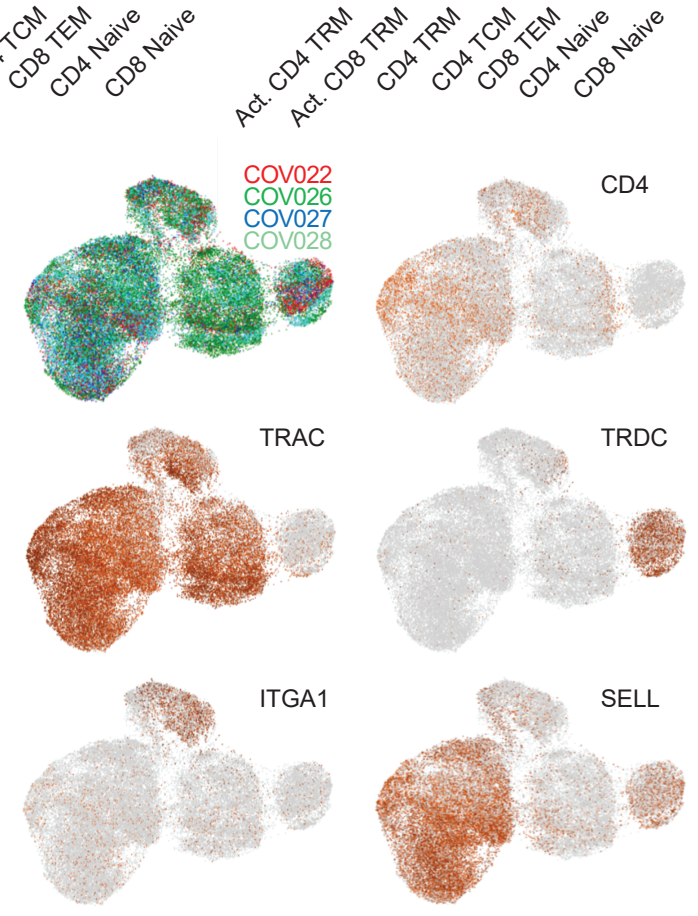

IL2RA
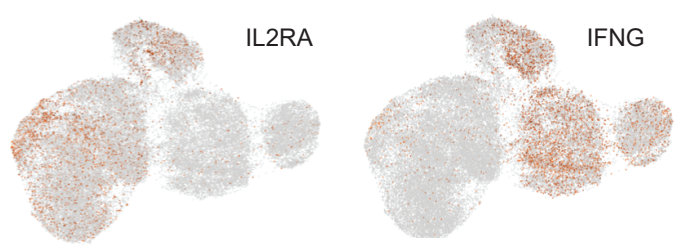
A

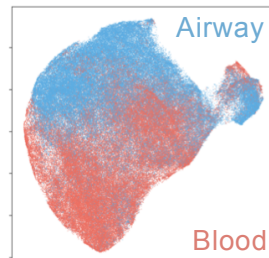

Blood

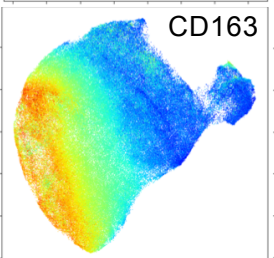

scaled expression

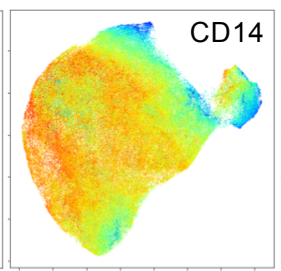

CD11C
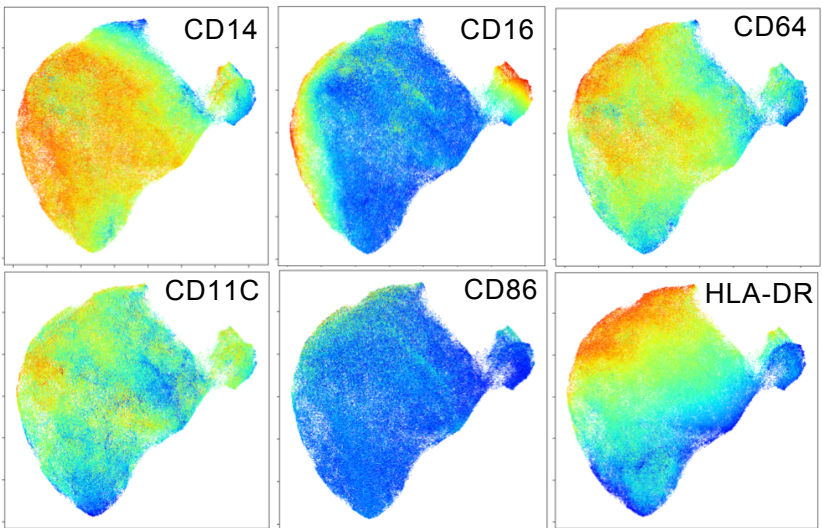

$\mathrm{C}$

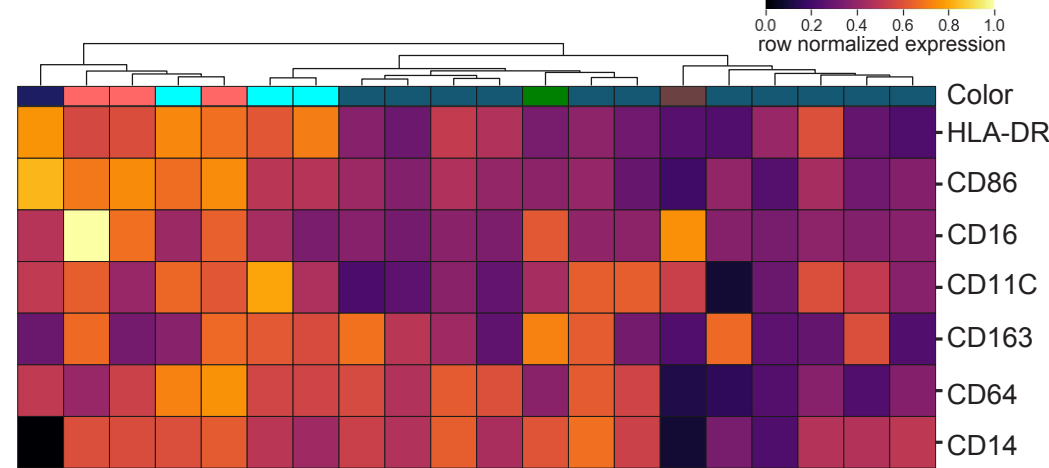

CD14

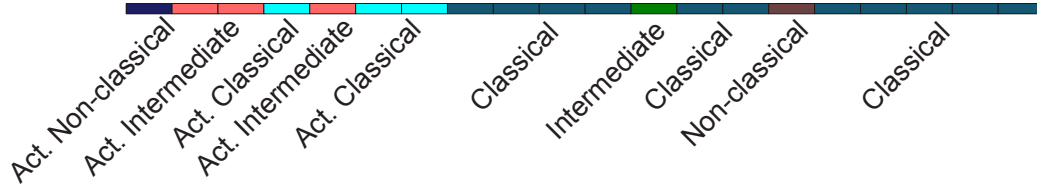

$\mathrm{E}$

Act.

Act. Classical Act. Intermediate Non-classical Classical
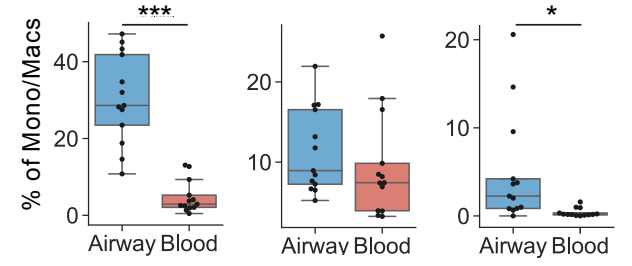

B
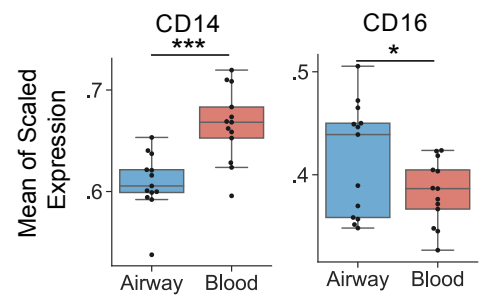

CD64

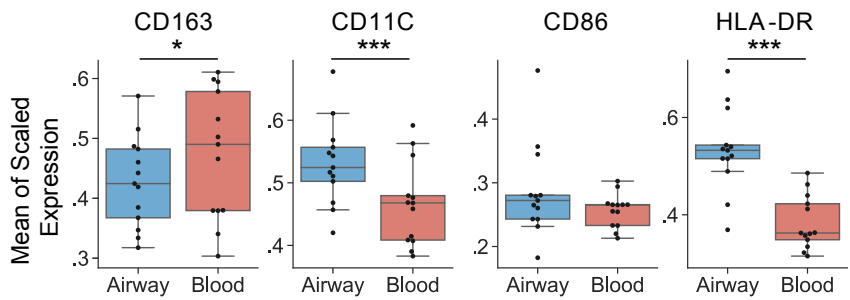

$\mathrm{D}$

\section{Airway}

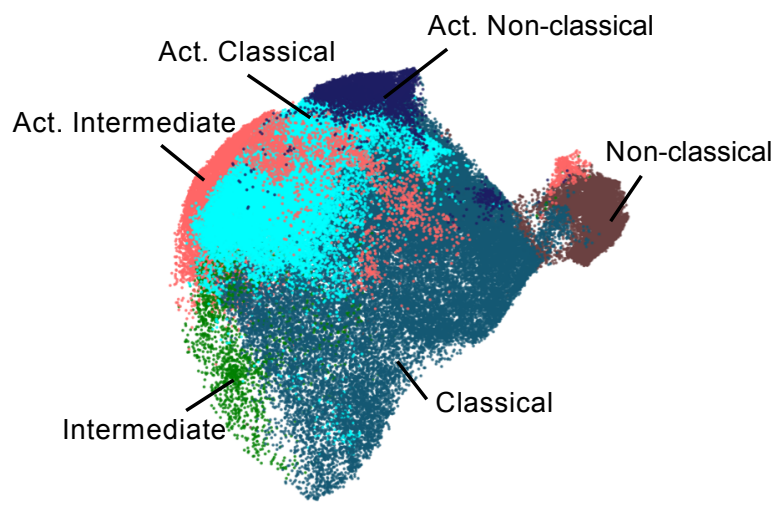

\section{Blood}

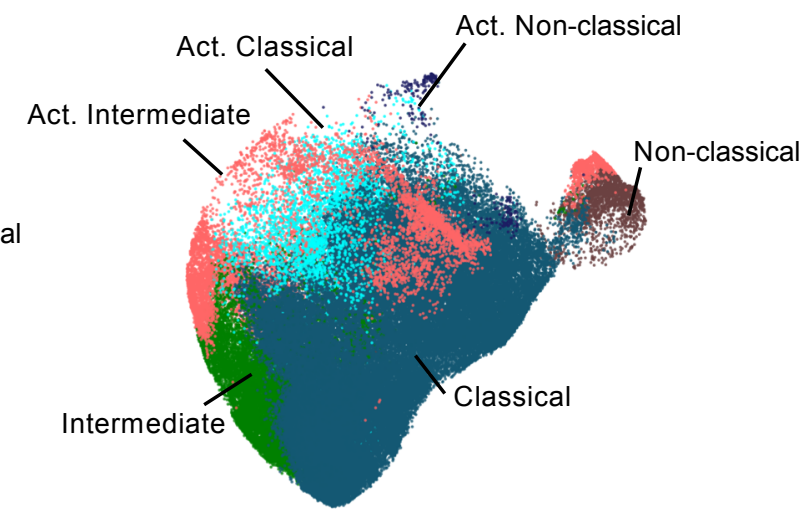




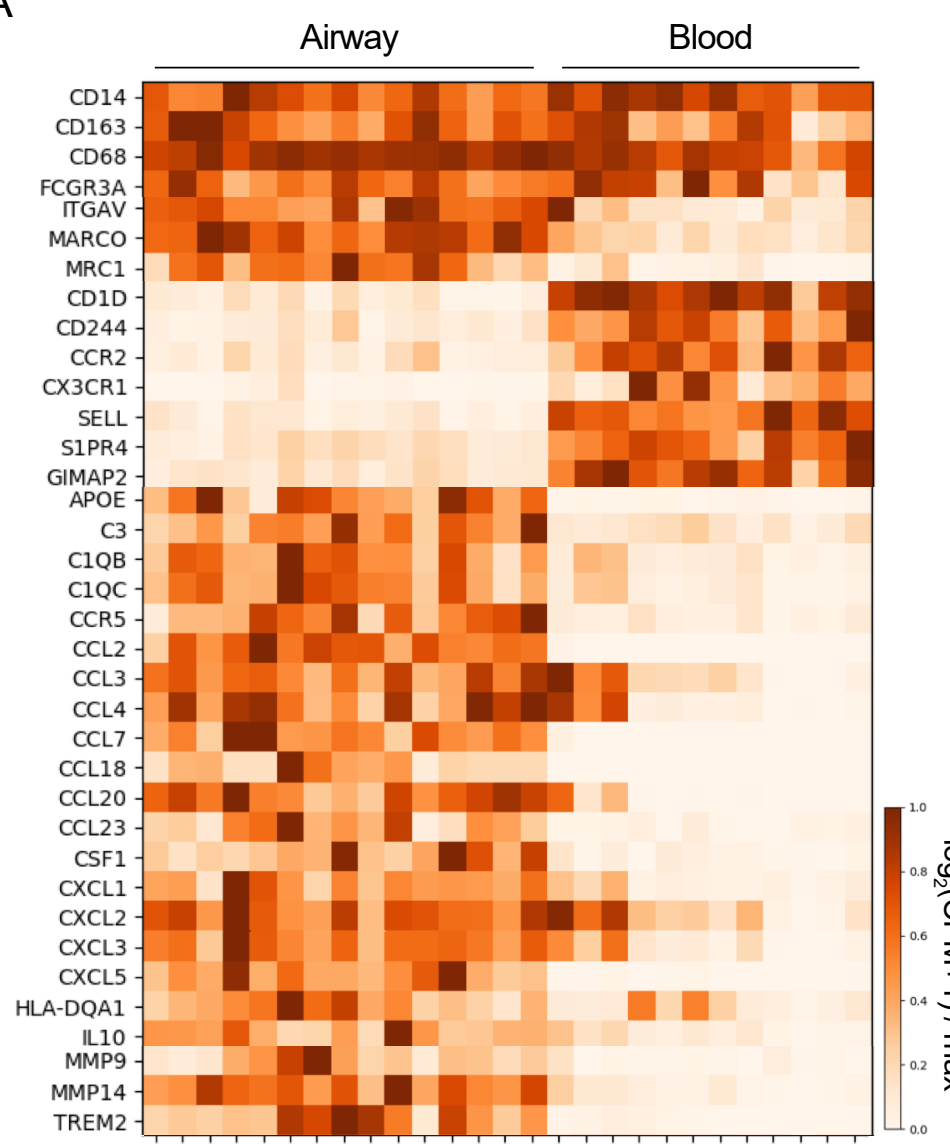

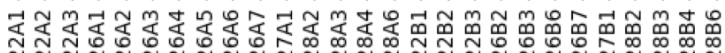

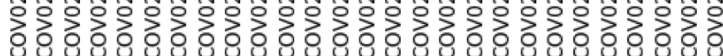

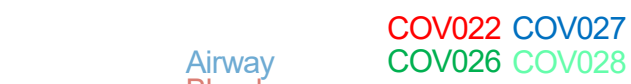

Figure 4.
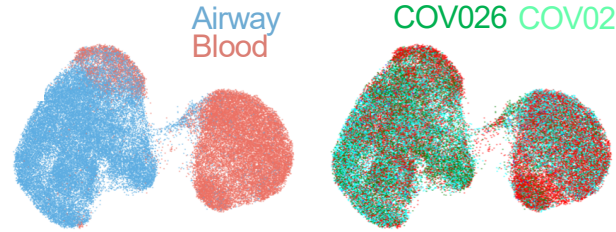

CD163
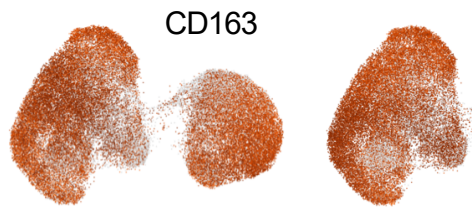

CD68

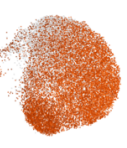

ITGAV
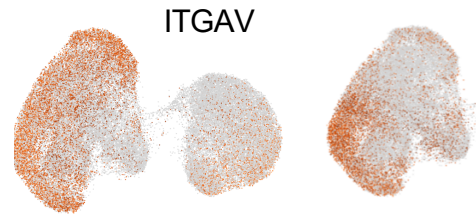

MRC1

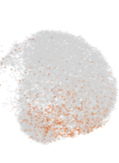

C1QC
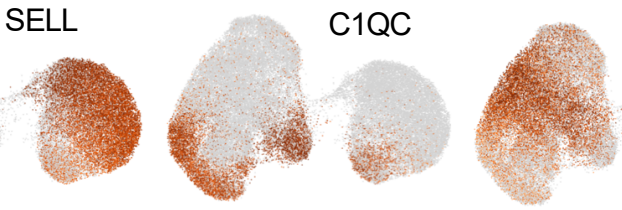

CCL20

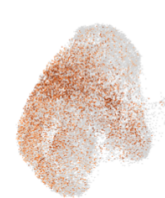

CXCL5

IFNB1

IFNG

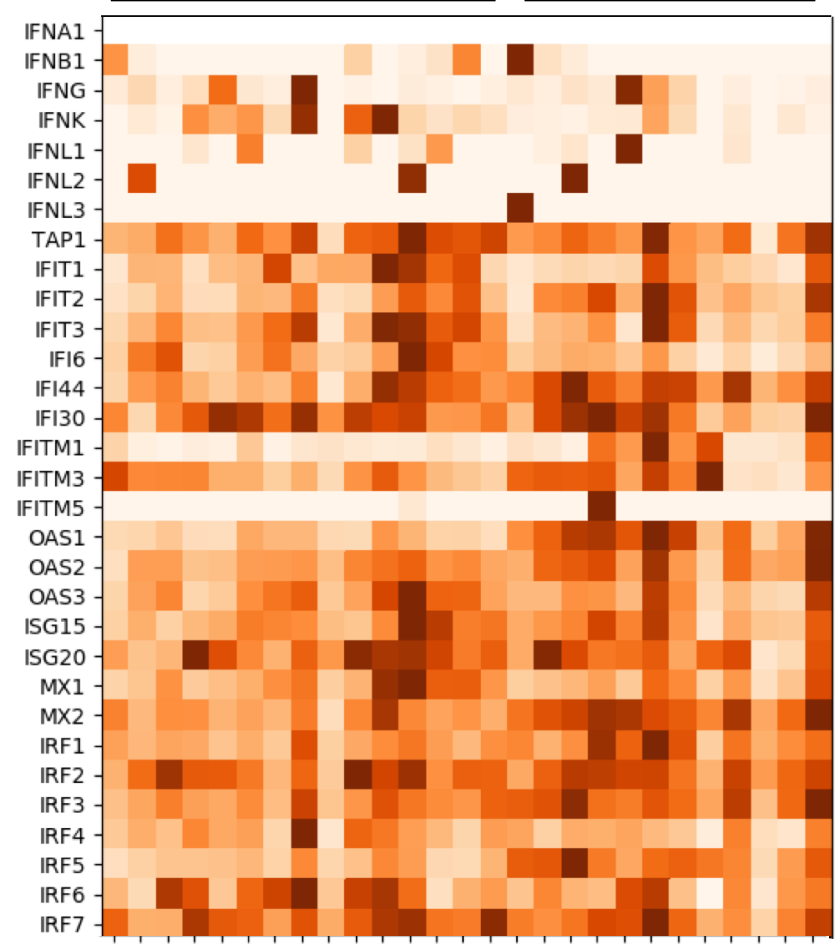

IFNA1

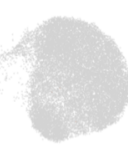

IFNK

IFNL1

IFIT3

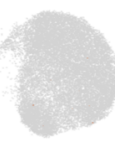

IFI6

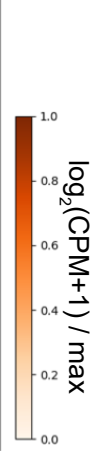

IFITM3
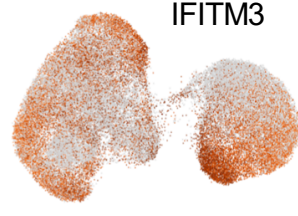

ISG15
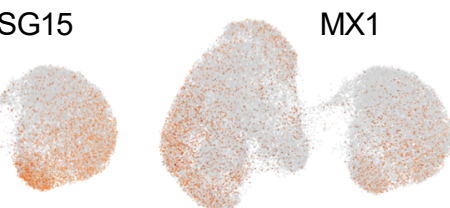

CCL2

CCR2

\section{MMP14}

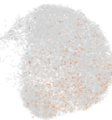



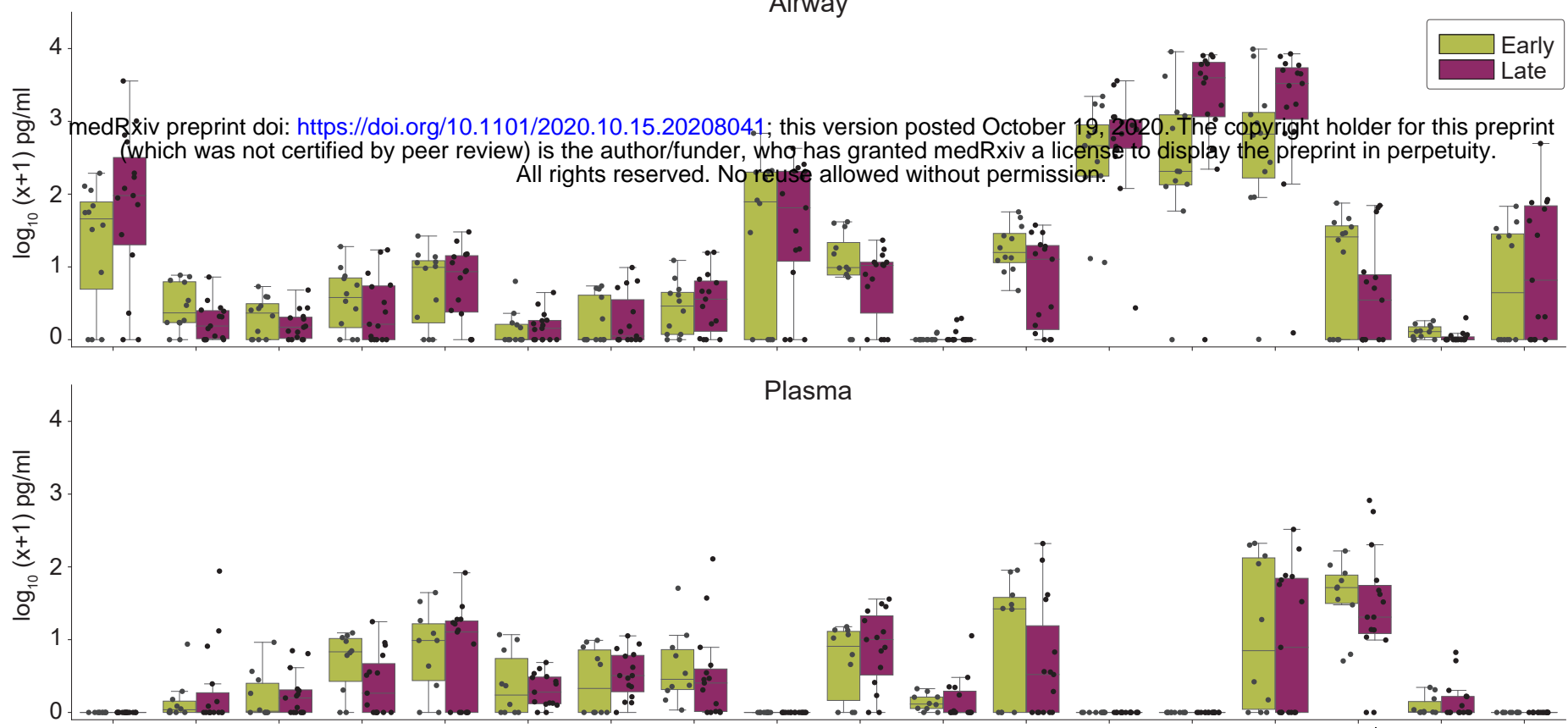

Plasma

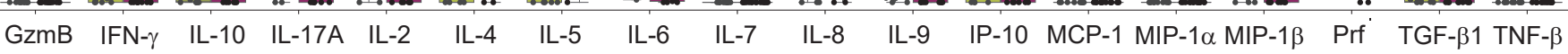
(CCL2) (CCL3) (CCL4)

B

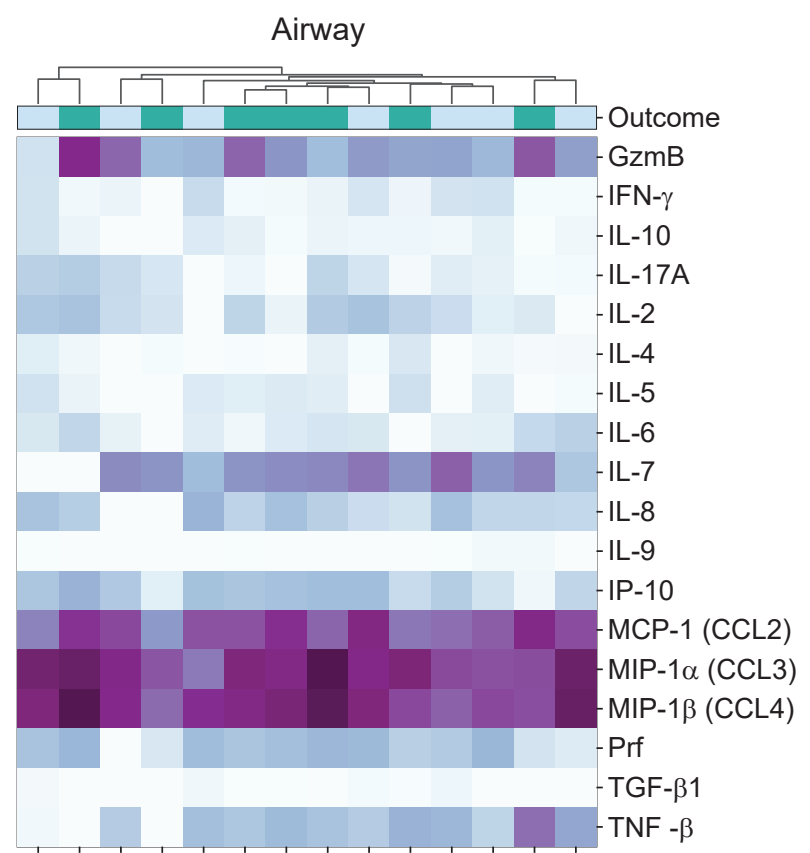

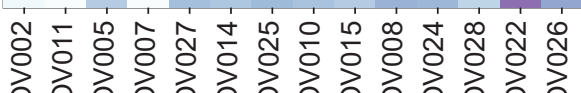
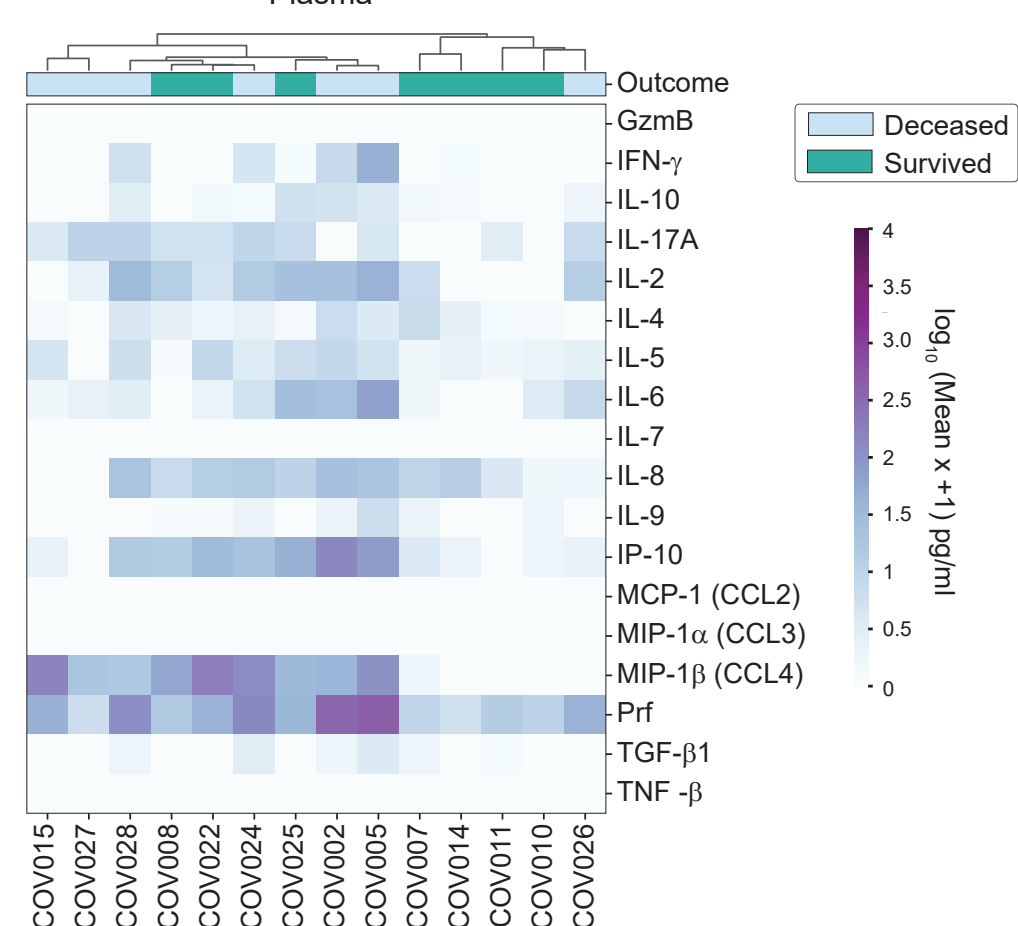

Plasma 
A COVID-19 and controls, 779855 cells
B $\quad$ Figure 6.

CD4 T cell

medRxiv preprint doi: https 100

/ 1000

(which was not certified by

Monocyte/macs

CD8 T cell ILC

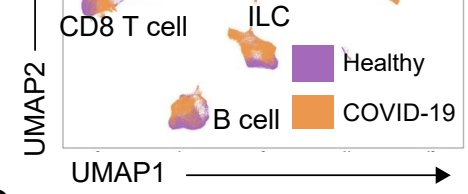

C

Healthy T cells
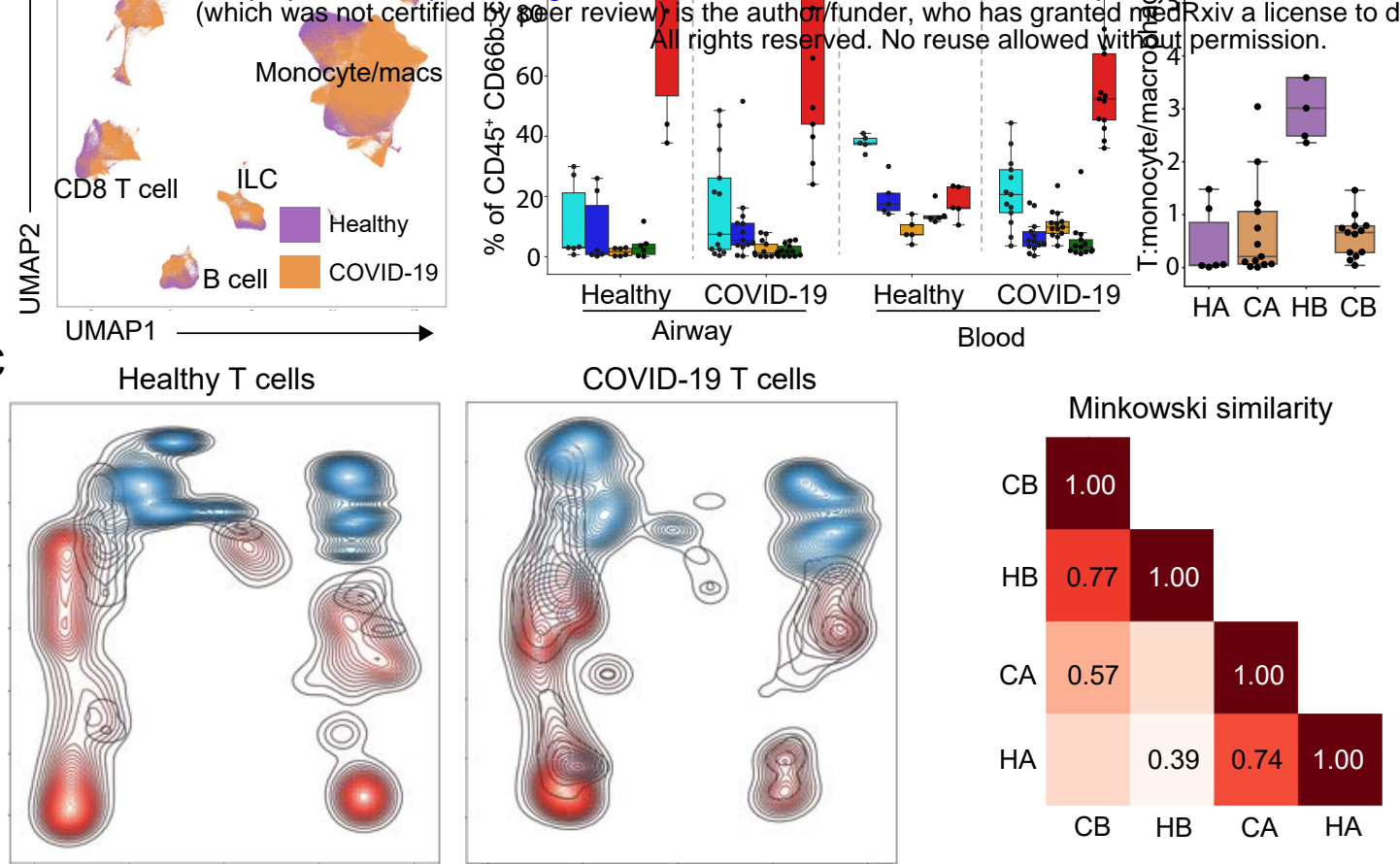

CoVID-19 T cells
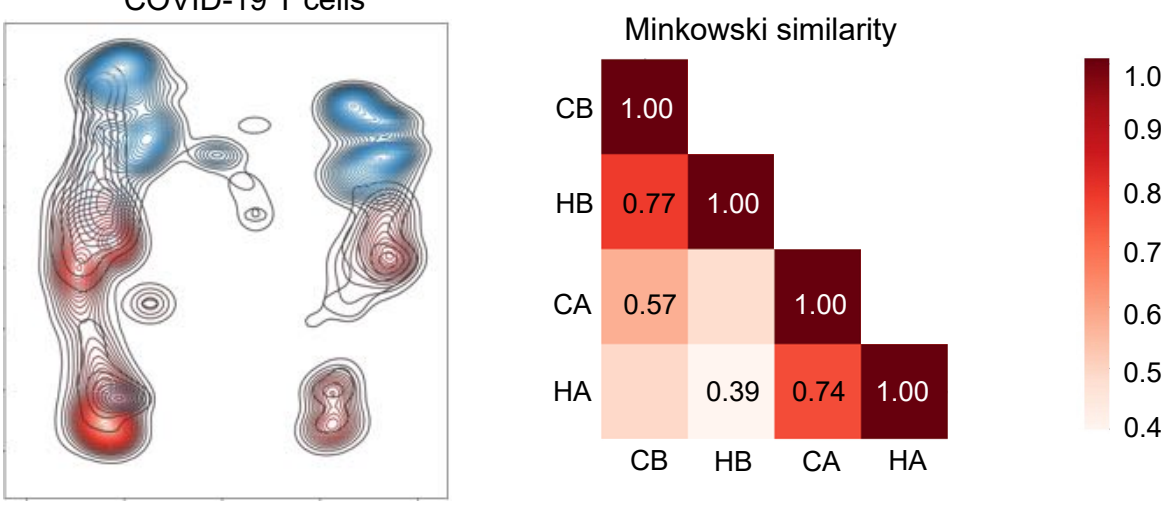

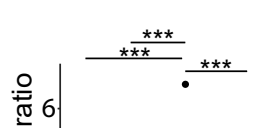
0.3

PCA by condition and site
(1 - Minkowski

distance) (MD)

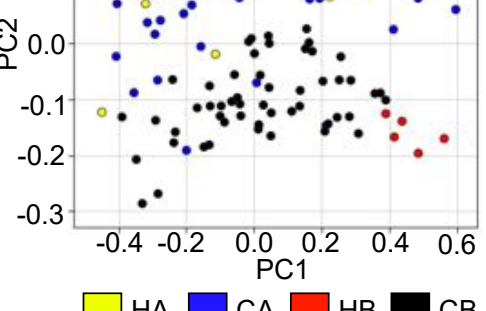

D

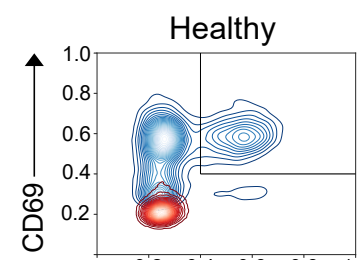

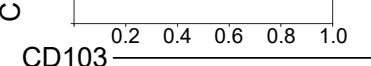

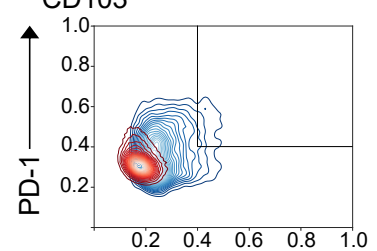

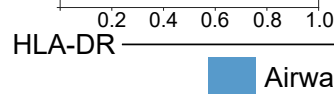

E

Healthy

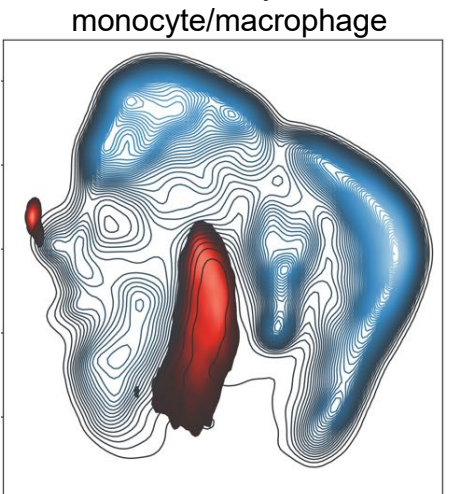

COVID-19
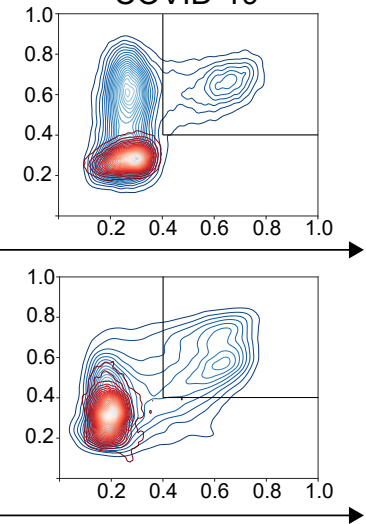

Blood

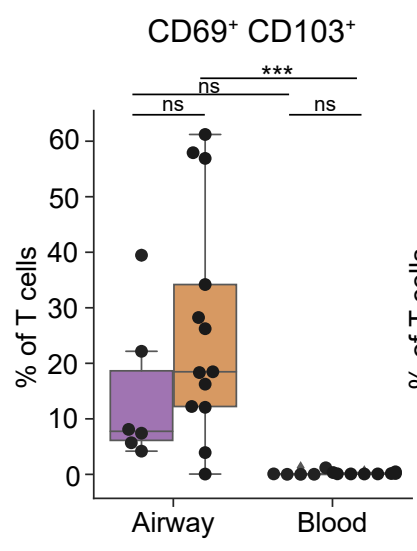

COVID-19

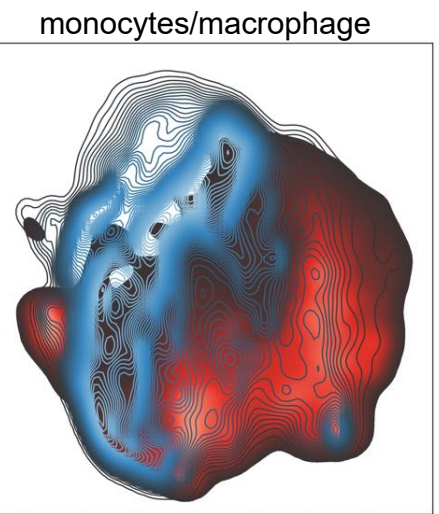

Minkowski similarity

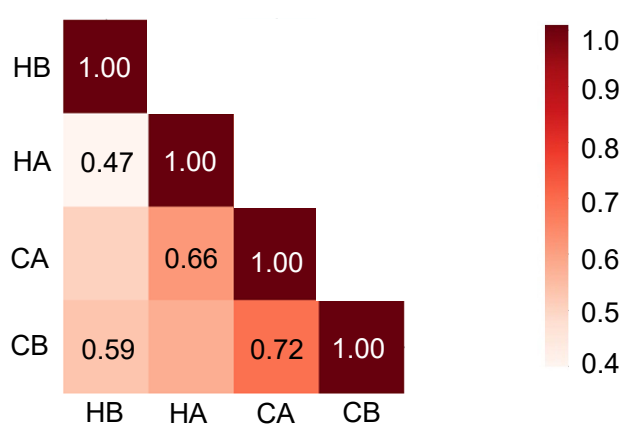

$\mathrm{HLA}^{-\mathrm{DR}^{+}}$
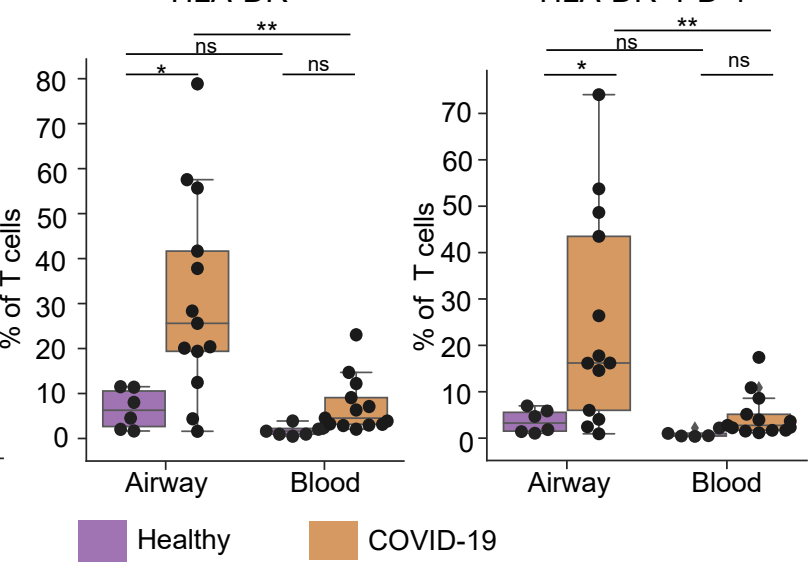

HLA-DR ${ }^{+}$PD-1+

\section{(1 - Minkowski}

distance) (MD)

F

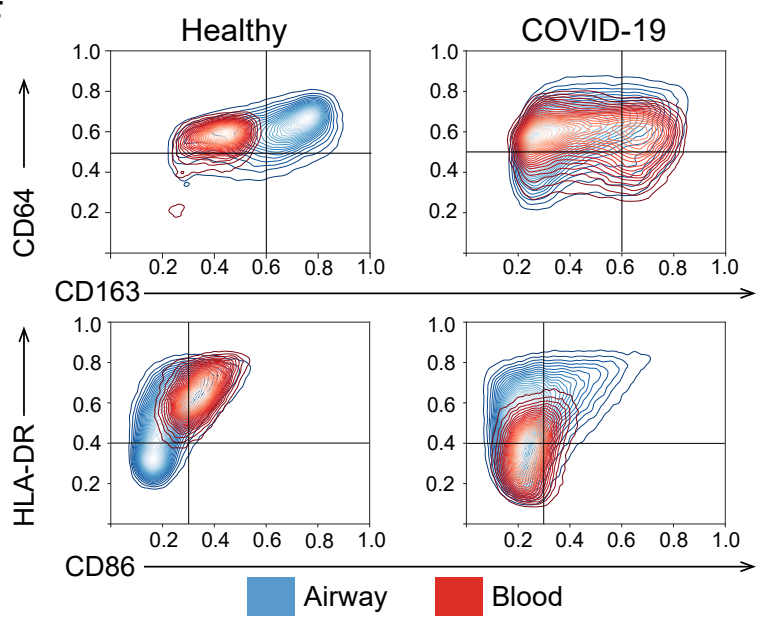

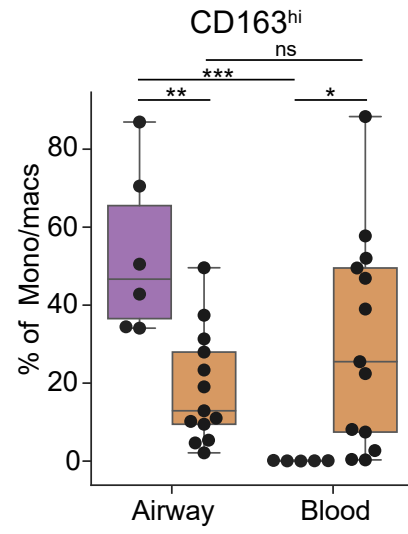
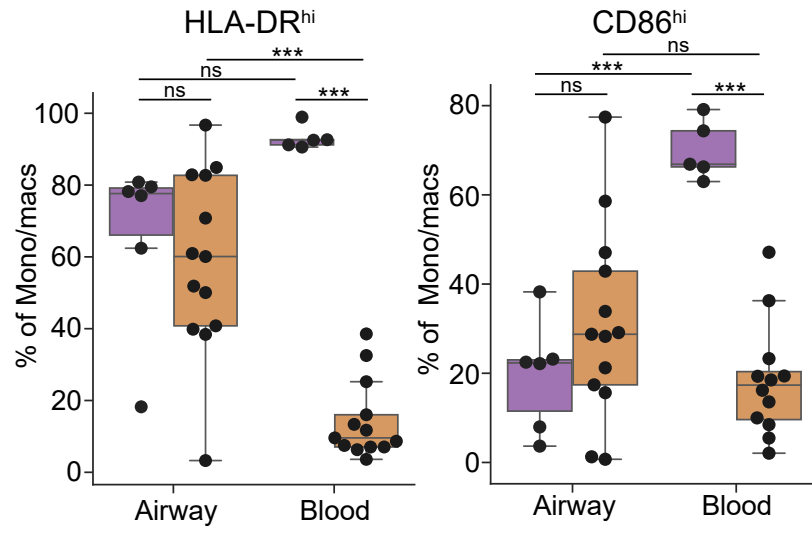
Control
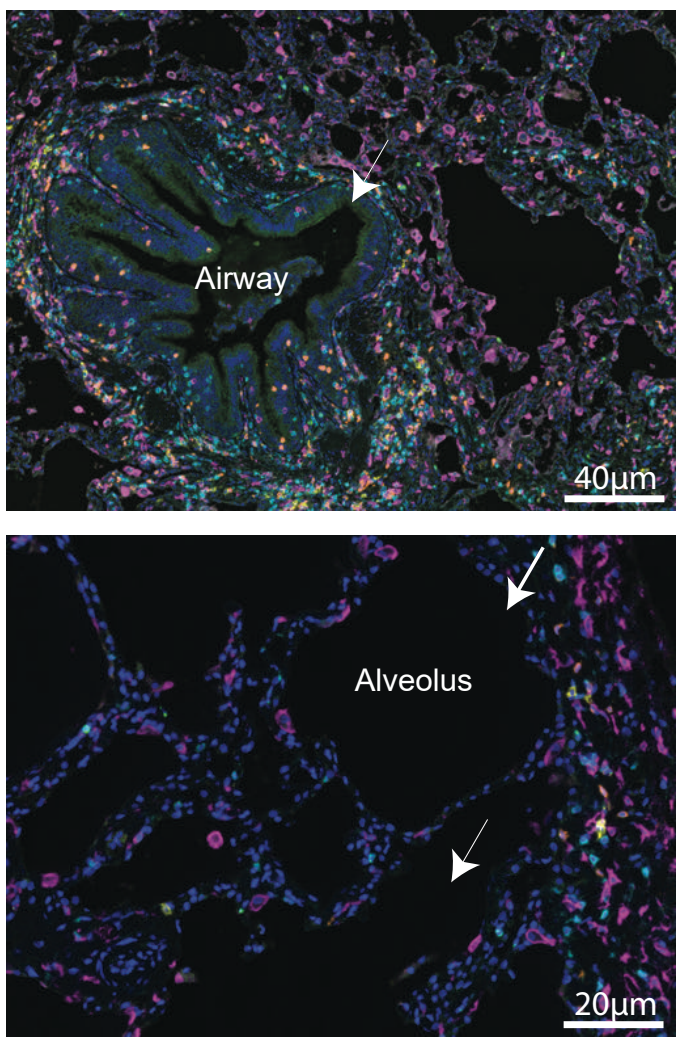

COVID-19
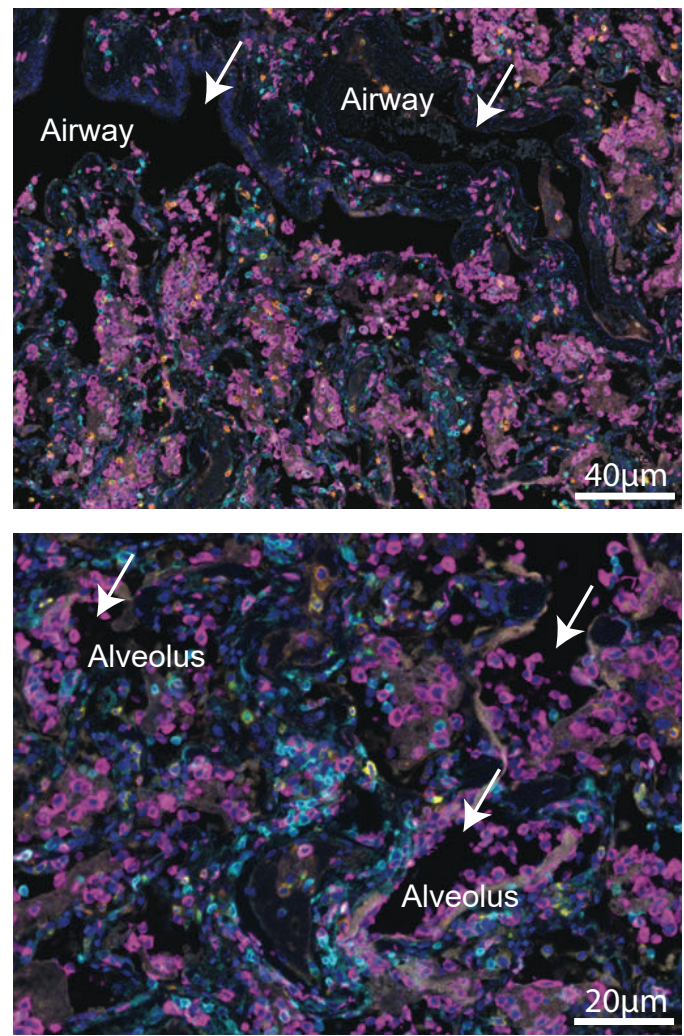

CD19 CD163 CD4 CD8 GzmB

B
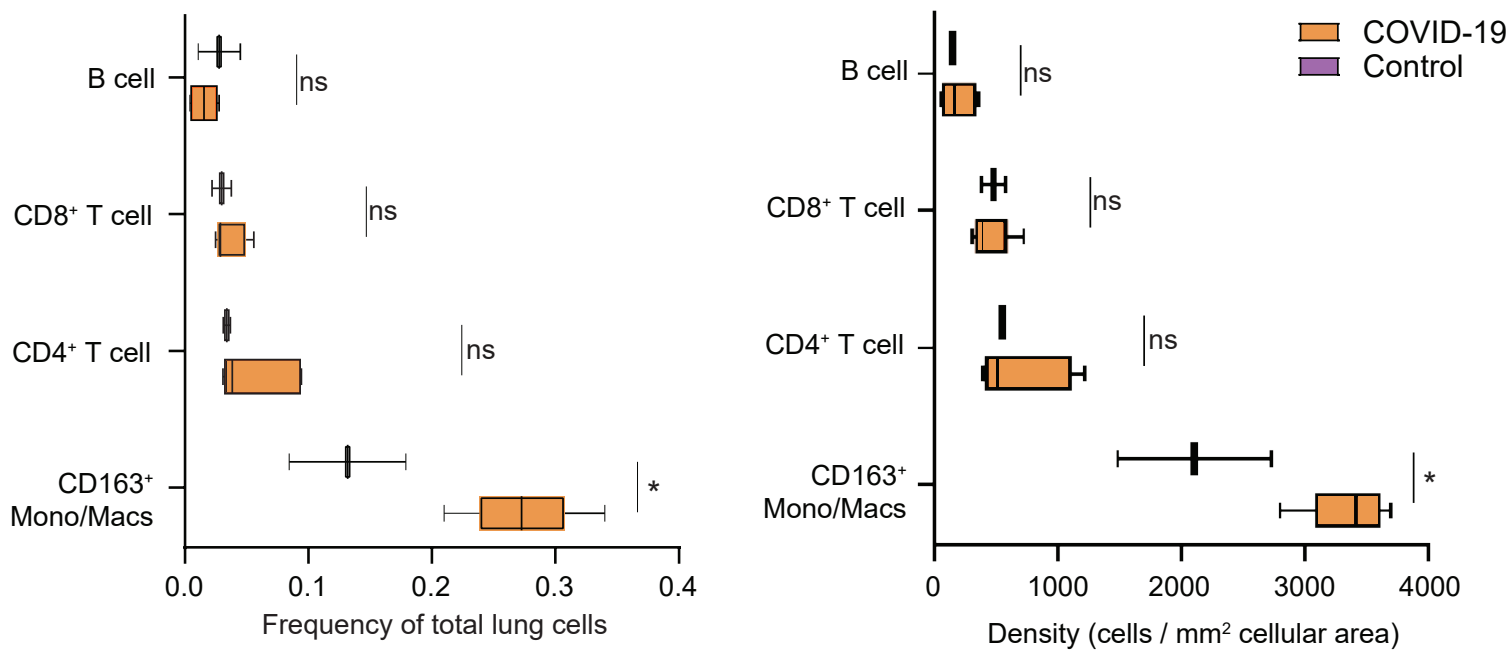

C

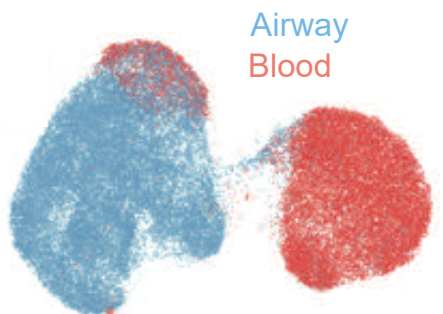

MKI67

TOP2A

UBE2C

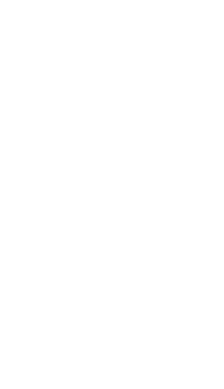

